\title{
Ferrocyanide Safety Project FY 1991 Annual Report
}

R. T. Hallen, Project Manager

L. L. Burger

R. L. Hockey

M. A. Lilga

R. D. Scheele

J. M. Tingey

June 1992

\author{
Prepared for \\ Westinghouse Hanford Company \\ Waste Tank Safety Program \\ with the U.S. Department of Energy \\ under Contract DE-AC06-76RLO 1830 \\ Pacific Northwest Laboratory \\ Operated for the U.S. Department of Energy \\ by Battelle Memorial Institute
}




\section{DISCLAIMER}

This report was prepared as an account of work sponsored by an agency of the United States Government. Neither the United States Government nor any agency Thereof, nor any of their employees, makes any warranty, express or implied, or assumes any legal liability or responsibility for the accuracy, completeness, or usefulness of any information, apparatus, product, or process disclosed, or represents that its use would not infringe privately owned rights. Reference herein to any specific commercial product, process, or service by trade name, trademark, manufacturer, or otherwise does not necessarily constitute or imply its endorsement, recommendation, or favoring by the United States Government or any agency thereof. The views and opinions of authors expressed herein do not necessarily state or reflect those of the United States Government or any agency thereof. 


\section{DISCLAIMER}

Portions of this document may be illegible in electronic image products. Images are produced from the best available original document. 


\title{
DISCLAIMER
}

This report was prepared as an account of work sponsored by an agency of the United States Government. Neither the United States Government nor any agency thereof, nor Battelle Memorial Institute, nor any of their employees, makes any warranty, expressed or implied, or assumes any legal liability or responsibility for the accuracy, completeness, or usefulness of any information, apparatus, product, or process disclosed, or represents that its use would not infringe privately owned rights. Reference herein to any specific commercial product, process, or service by trade name, trademark, manufacturer, or otherwise does not necessarily constitute or imply its endorsement, recommendation, or favoring by the United States Government or any agency thereof, or Battelle Memorial Institute. The views and opinions of authors expressed herein do not necessarily state or reflect those of the United States Government or any agency thereof.

\author{
PACIFIC NORTHWEST LABORATORY \\ operated by \\ BATTELLE MEMORIAL INSTITUTE \\ for the \\ UNITED STATES DEPARTMENT OF ENERGY \\ under Contract DE-AC06-76RLO 1830
}

Printed in the United States of America

Available to DOE and DOE contractors from the

Office of Scientific and Technical Information, P.O. Box 62, Oak Ridge, TN 37831; prices available from (615) 576-8401. FTS 626-8401.

Available to the public from the National Technical Information Service, U.S. Department of Commerce, 5285 Port Royal Rd., Springfield, VA 22161. 
Ferrocyanide Safety Project

FY 1991 Annual Report

R. T. Hallen, Project Manager

L. L. Burger

R. L. Hockey

M. A. Lilga

R. D. Scheele

J. M. Tingey

June 1992

Prepared for

Westinghouse Hanford Company

Waste Tank Safety Program

under Contract DE-AC06-76RLO 1830

with the U.S. Department of Energy

Pacific Northwest Laboratory

Richland, Washington 99352 


\section{Summary}

The Hanford Ferrocyanide Task Team is addressing issues involving ferrocyanide precipitates in the single-shell waste storage tanks (SSTs), in particular the risk of explosion. This Task Team, which is composed of researchers from Westinghouse Hanford Company (WHC), Pacific Northwest Laboratory (PNL), and outside consultants, was formed in response to the need for an updated analysis of safety questions on the Hanford SSTs.

The Ferrocyanide Safety Project, discussed in this report, is being conducted by PNL as part of the Waste Tank Safety Program led by WHC. The overall purpose of the WHC program, which is sponsored by the U.S. Department of Energy's Tank Safety Project Office, is to provide technical information on ferrocyanide chemistry and its interaction and reactive behavior with other tank constituents. Ultimately, this information will be used to maintain the tanks in a safe condition, implement interim stabilization strategies, and identify optimal disposal options.

While by itself ferrocyanide is a stable complex of ferrous ion and cyanide, it can be made to explode in the laboratory in the presence of oxidizing materials such as nitrates and/or nitrites at temperatures above $280^{\circ} \mathrm{C}$ or by sufficient electrical spark. The specific goal of the PNL project is to determine the conditions necessary for the ferrocyanide-bearing wastes in Hanford SSTs to represent a hazard, to determine the conditions where these same wastes are not a hazard, or to determine the conditions which are necessary to assure the wastes are safe prior to treatment for permanent disposal.

This annual report gives the results of the work conducted by PNL in FY 1991. The activities mainly focused on preparing and characterizing synthetic wastes and alkali nickel ferrocyanides produced using the In-Farm cesium scavenging flowsheet and pure potential nickel ferrocyanides that could be produced by all of the cesium scavenging flowsheets.

These preparation and characterization studies indicate that sodium nickel ferrocyanide was likely the predominant ferrocyanide precipitate produced by the In-Farm Flowsheet. These studies also indicate that dried, settled In-Farm Flowsheet solids are a near-stoichiometric mixture of ferrocyanide and the oxidants, sodium nitrate and nitrite, and exhibit a similar explosivity to washed sodium nickel ferrocyanide mixed with a stoichiometric amount of equimolar sodium nitrate and nitrite.

The differential scanning calorimetry (DSC) and scanning thermogravimetric (STG) studies indicate that the minimum exothermic reaction temperature for sodium nickel ferrocyanide and equimolar sodium nitrate and nitrite and dried, settled In-Farm Flowsheet solids is about $230^{\circ} \mathrm{C}$. In the PNL time-toexplosion (TTX) tests the minimum observed explosion temperature for these two mixtures was $310^{\circ} \mathrm{C}$; the results of this modified Henkin Test are dependent on the geometry and size of the test material. PNL also tested the explosivity of a sample of dried synthetic U-Plant waste prepared and provided by WHC. In the PNL TTX test the U-Plant waste did not explode at $400^{\circ} \mathrm{C}$ after heating for $20 \mathrm{~min}$.

Thermodynamic calculations to predict the effect of additional waste constituents on the reaction between $1 \mathrm{~g}$ of sodium nickel ferrocyanide and a stoichiometric amount of sodium nitrate indicate that small amounts of water and larger amounts of other potential waste constituents can prevent the reaction mixture from achieving high temperatures. It would require $3 \mathrm{~g}$ of water, $23.7 \mathrm{~g}$ of excess sodium nitrate, or $45 \mathrm{~g}$ of sodium aluminate to prevent temperatures from exceeding $200^{\circ} \mathrm{C}$ due to the heat of reaction. Lesser amounts of each of these diluents would allow temperatures to reach higher levels, thus allowing higher reaction rates. 
A mass spectrometer was used to monitor gaseous products produced by the thermal decomposition of simulated ferrocyanide-containing materials. A temperature-programmed microfurnace that simulated the temperature profile of STG and DSC experiments was interfaced to the mass spectrometer. The composition and relative abundance of gaseous products were found to be very dependent on the flowsheet used to prepare the ferrocyanide material.

Several useful techniques were identified for analyzing solid ferro- and ferricyanide materials. These techniques include infrared spectroscopy; $\mathrm{x}$-ray diffraction spectroscopy; environmental scanning electron microscopy/energy dispersive spectroscopy; and carbon, hydrogen, nitrogen elemental analyses. Combined, these techniques provided molecular, elemental, and functional group data that were used to speciate several synthetic materials and compile a spectral and analytical database.

Work is continuing on the behavior of ferrocyanide compounds in the presence of nitrate/nitrite. Studies will involve preparation and characterization of simulated waste, aging mechanisms, chemical reactivity and explosivity (including catalysts and initiators), and effect of diluents. 


\section{Contents}

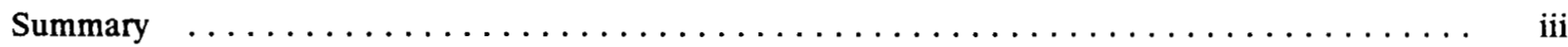

Acronyms $\ldots \ldots \ldots \ldots \ldots \ldots \ldots \ldots \ldots \ldots \ldots \ldots \ldots \ldots \ldots \ldots \ldots \ldots \ldots \ldots \ldots \ldots \ldots \ldots \ldots$

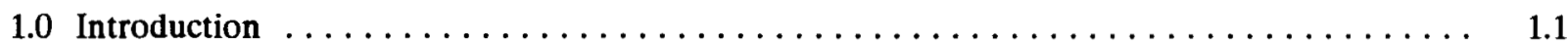

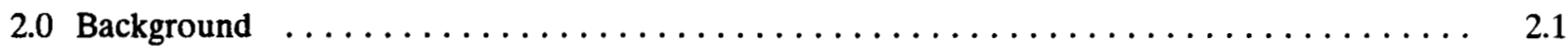

3.0 Results of Past Studies $\ldots \ldots \ldots \ldots \ldots \ldots \ldots \ldots \ldots \ldots \ldots \ldots \ldots \ldots \ldots \ldots \ldots \ldots \ldots \ldots \ldots \ldots .1$

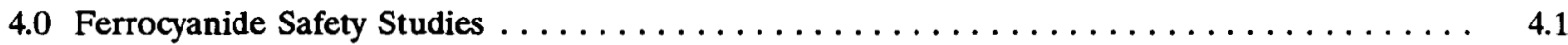

4.1 Preparation and Characterization of Simulated Ferrocyanide-Containing Wastes $\ldots \ldots \quad 4.1$

4.1.1 Work Accomplished $\ldots \ldots \ldots \ldots \ldots \ldots \ldots \ldots \ldots \ldots \ldots \ldots \ldots \ldots \ldots \ldots \ldots \ldots \ldots$

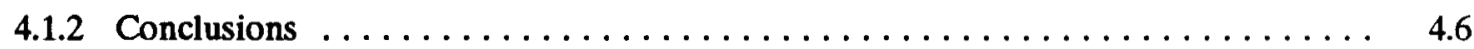

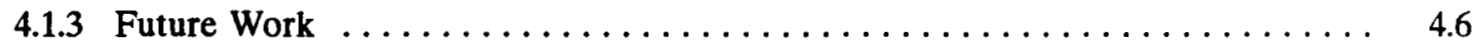

4.2 Chemical Nature of Iron and Cyanide in Wastes $\ldots \ldots \ldots \ldots \ldots \ldots \ldots \ldots \ldots$

4.2.1 Work Accomplished $\ldots \ldots \ldots \ldots \ldots \ldots \ldots \ldots \ldots \ldots \ldots \ldots \ldots \ldots \ldots \ldots$

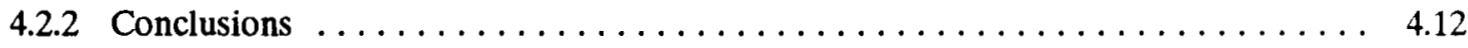

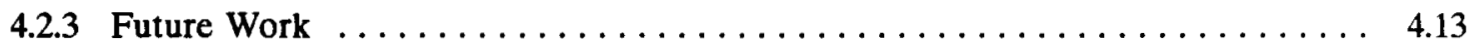

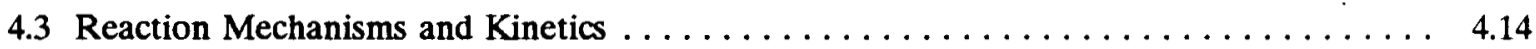

4.3.1 Work Accomplished $\ldots \ldots \ldots \ldots \ldots \ldots \ldots \ldots \ldots \ldots \ldots \ldots \ldots \ldots \ldots \ldots \ldots$

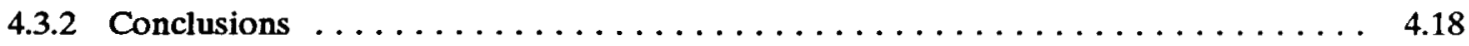

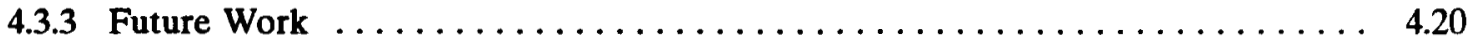

4.4 Energetic Studies of Ferrocyanide-Containing Wastes $\ldots \ldots \ldots \ldots \ldots \ldots \ldots \ldots \ldots .22$

4.4.1 Work Accomplished $\ldots \ldots \ldots \ldots \ldots \ldots \ldots \ldots \ldots \ldots \ldots \ldots \ldots \ldots \ldots \ldots \ldots$

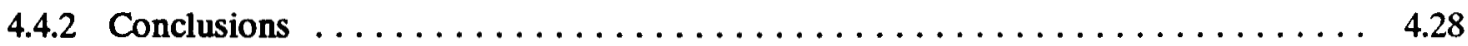

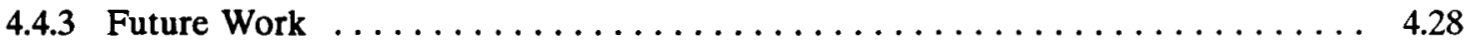


4.5 Ferrocyanide Detection and In-Situ Waste Characterization: Development of an Electromagnetic Induction Method for Measuring Water Concentration

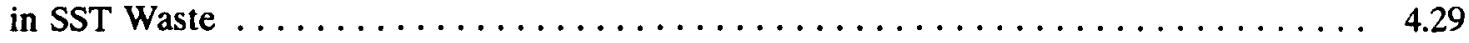

4.5.1 Work Accomplished $\ldots \ldots \ldots \ldots \ldots \ldots \ldots \ldots \ldots \ldots \ldots \ldots \ldots \ldots \ldots .29$

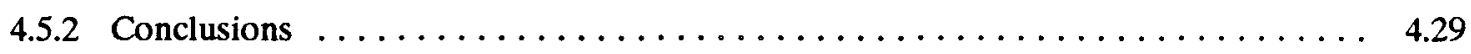

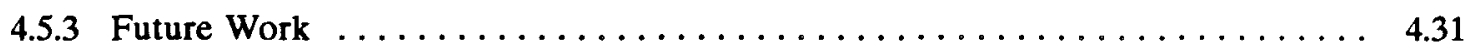

4.6 Tank Waste Science Panel $\ldots \ldots \ldots \ldots \ldots \ldots \ldots \ldots \ldots \ldots \ldots \ldots \ldots \ldots \ldots \ldots \ldots$

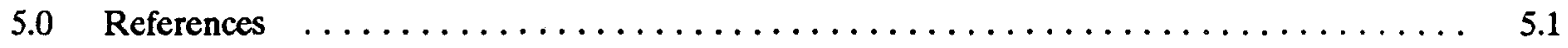




\section{Figures}

2.1 Ferrocyanide Scavenging to Remove Cesium $\ldots \ldots \ldots \ldots \ldots \ldots \ldots \ldots \ldots \ldots \ldots \ldots \ldots$

4.1 X-ray Diffraction Spectrum of the In-Farm Flowsheet Prepared Ferrocyanide

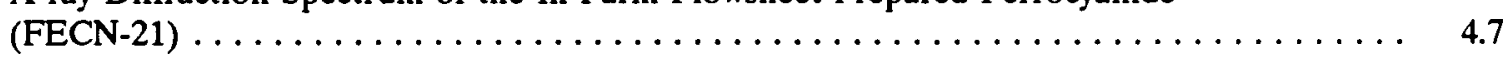

4.2 Environmental Scanning Electron Microscopy Data of WHC-2 $\ldots \ldots \ldots \ldots \ldots \ldots \ldots$

4.3 Infrared Spectrum (KBr Pellet) of FECN-21 $\ldots \ldots \ldots \ldots \ldots \ldots \ldots \ldots \ldots \ldots \ldots \ldots$

4.4 Powder X-ray Diffraction Results for FECN-21 $\ldots \ldots \ldots \ldots \ldots \ldots \ldots \ldots \ldots \ldots \ldots \ldots$

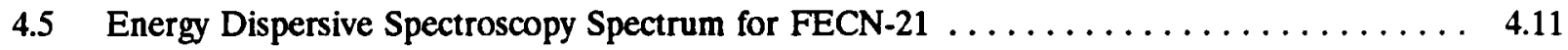

4.6 Mössbauer Spectrum and Model Fit for $60 \% \mathrm{~K}_{3} \mathrm{Fe}(\mathrm{CN})_{6} / 40 \% \mathrm{~K}_{4} \mathrm{Fe}(\mathrm{CN})_{6} \ldots \ldots \ldots .14$

4.7 Duplicate Experiments of Different Sample Sizes Showing Total Ion Traces for the Thermal Decomposition of Washed In-Farm Flowsheet Ferrocyanide Solids (FECN-19) ...

4.8 Extracted Ion Traces for the Major Mass Ions $(18,28,30$, and 44) for the Thermal Decomposition of Washed In-Farm Flowsheet Solids (FECN-19) $\ldots \ldots \ldots \ldots \ldots \ldots$

4.9 Extracted Ion Traces for Carbon (Mass 12), Nitrogen (Mass 14), and Oxygen (Mass 16) from the Thermal Decomposition of Washed In-Farm Ferrocyanide

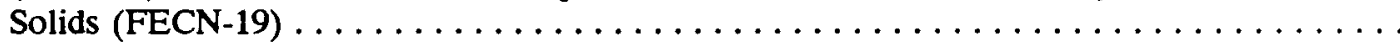

4.10 Extracted Ion Traces for Mass Ions 26, 27, and 52 from the Thermal Decomposition of Washed In-Farm Ferrocyanide Solids (FECN-19) . . . . . . . . . . . . . . . . . .

4.11 Total Ion Traces for the Thermal Decomposition of Flowsheet Materials: FECN-19, FECN-21, WHC-1, and FECN-28b Plus Nitrate/Nitrite $\ldots \ldots \ldots \ldots \ldots \ldots \ldots$

4.12 Extracted Ion Traces for Mass Ion 28 for the Thermal Decomposition of Flowsheet

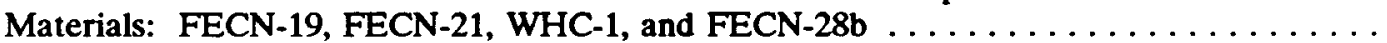

4.13 Time-to-Explosion Data for FECN-21, WHC-1, and FECN-19 Mixed with Equimolar Sodium Nitrate/Nitrite.

4.14 Differential Scanning Calorimetry of Settled and Dried Sodium Nickel Ferrocyanide Prepared Using In-Farm and U-Plant Flowsheets

4.15 Scanning Thermogravimetry of Settled and Dried Sodium Nickel Ferrocyanide Prepared Using In-Farm Flowsheet . . . . . . . . . . . . . . . . . . . . . . 4.27

4.16 Equipment for Moisture Measurement Studies $\ldots \ldots \ldots \ldots \ldots \ldots \ldots \ldots \ldots \ldots \ldots$

4.17 Magnitude and Phase of the Coil Electrical Impedance Versus Frequency . . . . . . . 4.30 


\section{Tables}

3.1 Heats of Reaction for Different Oxidation Reactions $\ldots \ldots \ldots \ldots \ldots$

4.1 Ferro- and Ferricyanide Preparation Method $\ldots \ldots \ldots \ldots \ldots$

4.2 Two Nominal Ferrocyanide Scavenging Flowsheets $\ldots \ldots \ldots \ldots . \ldots$

4.3 Ferro- and Ferricyanide Washing Methods $\ldots \ldots \ldots \ldots \ldots \ldots \ldots$

4.4 Measured Compositions for Ferro- and Ferricyanide Compounds $\ldots \ldots \ldots$

4.5 Carbon, Hydrogen, Nitrogen Elemental Analyses Results for FECN-21, Flowsheet $\mathrm{Na}_{2} \mathrm{NiFe}(\mathrm{CN})_{6} \ldots \ldots \ldots \ldots \ldots \ldots \ldots \ldots \ldots \ldots \ldots \ldots \ldots \ldots$

4.6 Nominal Compositions of Synthetic Ferrocyanide Materials $\ldots \ldots \ldots . \ldots$

4.7 Calculated Enthalpy Changes for Oxidation of Some Cyanides and Ferrocyanides . . . . . 4.23

4.8 Estimated Quantity of Diluent Required to Prevent Propagation of Ferrocyanide

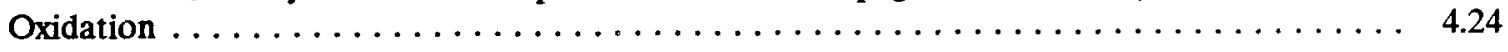

4.9 Time-to-Explosion Data for Small Samples $\ldots \ldots \ldots \ldots \ldots \ldots \ldots \ldots$ 


\section{Acronyms}

\begin{tabular}{|c|c|}
\hline $\mathrm{CHN}$ & carbon, hydrogen, nitrogen elemental analyses \\
\hline $\mathrm{CN}$ & cyanide \\
\hline DNFSB & Defense Nuclear Facilities Safety Board \\
\hline DOE & U.S. Department of Energy \\
\hline DSC & differential scanning calorimetry \\
\hline DXRD & Dynamic XRD \\
\hline EDS & energy dispersive spectroscopy \\
\hline EDTA & tetrasodium ethylenediaminetetraacetate acid \\
\hline EIS & Environmental Impact Statement \\
\hline ESCA & electron spectroscopy for chemical analysis \\
\hline ESEM & environmental scanning electron microscopy \\
\hline FTIR & fourier transform infrared spectroscopy \\
\hline GAO & General Accounting Office \\
\hline GC-MS & gas chromatograph-mass spectrometer \\
\hline $\mathrm{HCN}$ & hydrogen cyanide \\
\hline IC & ion chromatography \\
\hline ICDD & International Center for Diffraction Data \\
\hline ICP/AES & inductively coupled argon plasma/atomic emission spectroscopy \\
\hline IR & infrared spectroscopy \\
\hline JCPDS & Joint Committee on Powder Diffraction Standards \\
\hline $\mathrm{KCN}$ & potassium cyanide \\
\hline LANL & Los Alamos National Laboratory \\
\hline MS & mass spectrometer \\
\hline NMR & nuclear magnetic resonance \\
\hline OD & outside diameter \\
\hline PNL & Pacific Northwest Laboratory \\
\hline SS & stainless steel \\
\hline SST & single-shell storage tank at Hanford \\
\hline STG & scanning thermogravimetry \\
\hline TBP & tributyl phosphate \\
\hline TOC/TIC/TC & total organic carbon/total inorganic carbon/total carbon \\
\hline TTX & time-to-explosion \\
\hline WHC & Westinghouse Hanford Company \\
\hline XRD & x-ray diffraction spectroscopy \\
\hline
\end{tabular}




\subsection{Introduction}

Various efforts have been under way since the mid 1980 s to evaluate the potential for a ferrocyanide explosion in the single-shell waste storage tanks (SSTs) at the U.S. Department of Energy (DOE) Hanford Site (Burger 1984; Burger and Scheele 1988). In 1987, the Environmental Impact Statement (EIS), Disposal of Hanford Defense High-Level, Transuranic and Tank Wastes (DOE 1987), projected that a "worstcase" explosion in a ferrocyanide tank would result in a subsequent short-term radiation dose of 200 mrem to the public. In a more recent study by the General Accounting Office (GAO) (Peach 1990) a "worstcasen $^{n}$ accident was postulated with independently calculated doses of 1 to 2 orders of magnitude greater than the 1987 EIS. A special Hanford Ferrocyanide Task Team was subsequently commissioned (September 1990) to address all issues involving the ferrocyanide tanks, including the consequences of a potential accident.

On October 9, 1990, Secretary of Energy James D. Watkins announced that a Supplemental EIS would be prepared that would contain an updated analysis of safety questions for the Hanford SSTs (including a ferrocyanide explosion) (DOE 1990). The efforts described in this annual report are part of a study to provide the primary technical input required for the ferrocyanide explosion portion of the Supplemental EIS. Westinghouse Hanford Company (WHC) has the overall program responsibility, with supporting work by Pacific Northwest Laboratory (PNL). ${ }^{\text {(a) }}$

The Hanford Ferrocyanide Task Team is composed of technical experts from both WHC and PNL. In addition, outside consultants are providing further expertise in the fields of ferrocyanide chemistry, behavior of ferrocyanides as explosives, and behavior of aerosols formed from an explosion. The Ferrocyanide Team reports to the DOE Richland Field Office, Tank Safety Project Office, through the Ferrocyanide Stabilization function within the WHC Waste Tank Safety Program.

This annual report discusses work performed in FY 1991 for the Ferrocyanide Safety Project, which is being conducted by PNL. The study reported here has been divided into the following tasks:

Task 1 Project and Program Management

Task 2 Preparation and Characterization of Simulated Ferrocyanide-Containing Wastes

Task 3 Chemical Nature of Iron and Cyanide in Wastes/Reaction Mechanisms and Kinetics

Task 4 Energetic Studies of Ferrocyanide-Containing Wastes

Task 5 Ferrocyanide Detection and In-Situ Waste Characterization

Task 6 Tank Waste Science Panel.

Along with discussions on the individual tasks, this report contains background information on the tanks and results of earlier studies to provide an overview of the problems being addressed. Reports for the Science Panel have been published separately (Burger et al. 1991; Strachan 1991).

(a) Operated for the U.S. Department of Energy by Battelle Memorial Institute under Contract DE-AC06-76RLO 1830. 


\subsection{Background}

Radioactive wastes from defense operations have been stored at the Hanford Site in underground waste tanks since the early 1940 s. Over the years, wastes have been distributed among tanks to segregate different types of waste and to reduce the need for additional tanks. For example, during the 1950s, additional storage volume was needed to support the defense mission within a short period of time and without constructing more storage tanks. Consequently, Hanford scientists developed a process to scavenge radiocesium from either dissolved wastes or waste liquids already stored in the tanks. This process involved the carrier precipitation of cesium nickel ferrocyanide; an example flowsheet is shown in Figure 2.1 (Burger et al. 1991). Decontaminated supernate was then pumped to a crib. While providing more storage within the tanks, this process eventually added approximately 150 metric tons (Borsheim and Simpson 1991) of ferrocyanide [as $\mathrm{Fe}(\mathrm{CN})_{6}{ }^{-4}$ ion] to the SSTs.

There were three flowsheets used to scavenge the radiocesium from aqueous wastes. The first was used to treat first-cycle waste from the Bismuth Phosphate Process (T-Plant Flowsheet). This generated $10 \%$ of the total ferrocyanide waste. The second, the U-Plant Flowsheet, treated "metal waste" dissolved in nitric acid after the uranium had been recovered using the Tributyl Phosphate (TBP) Process; this flowsheet produced $70 \%$ of the total ferrocyanide waste. The third process, the In-Farm Flowsheet, treated the basic waste from the uranium recovery process, which was stored in the Hanford tanks, and produced $20 \%$ of the total ferrocyanide waste.

The first two flowsheets treated wastes containing substantial metal concentrations which when neutralized with sodium hydroxide would precipitate, subsequently diluting the ferrocyanide. Dilution of the ferrocyanide assumes that the hydroxide solids settled similarly to the ferrocyanide solids. Thus, these first two flowsheets would have a significantly lower concentration of ferrocyanide than the In-Farm Flowsheet waste.

Of the 177 waste storage tanks present on the site, 149 are SSTs. Records at Hanford show 24 SSTs contain at least $200 \mathrm{~kg}$ (1000 g-mol) of ferrocyanide precipitates. The ferrocyanide content of the individual tanks ranges from $200 \mathrm{~kg}$ up to possibly $17,000 \mathrm{~kg}$ (in Tank BY-104) of ferrocyanide calculated as the Fe anion. Other wastes in these tanks probably include sodium nitrate, sodium nitrite, silicates, aluminates, hydroxides, phosphates, sulfates, carbonates, uranium, copper, and calcium in addition to the fission products present from the processing of irradiated fuel.

Ferrocyanide by itself is a stable complex of ferrous ion and cyanide that is considered nontoxic because it does not dissociate in aqueous solutions. However, in the laboratory, in the presence of oxidizing materials such as nitrates and/or nitrites, ferrocyanide can be made to explode by heating to high temperatures (above $280^{\circ} \mathrm{C}$ ) or by an electrical spark of sufficient energy (Burger and Scheele 1991). The explosive nature of ferrocyanide in the presence of an oxidizer has been known for decades, but the conditions under which the compound can undergo an uncontrolled exothermic reaction have not been thoroughly studied. Explosion propagation properties for large quantities of the material are unknown. Also largely unknown are the effects of moisture content and other diluents (or possible catalysts or initiators) that may be present. Because the scavenging process involved precipitating ferrocyanide from solutions containing nitrate and nitrite, it is likely that an intimate mixture of ferrocyanides and nitrates/nitrites exists in parts of some of the SSTs. 


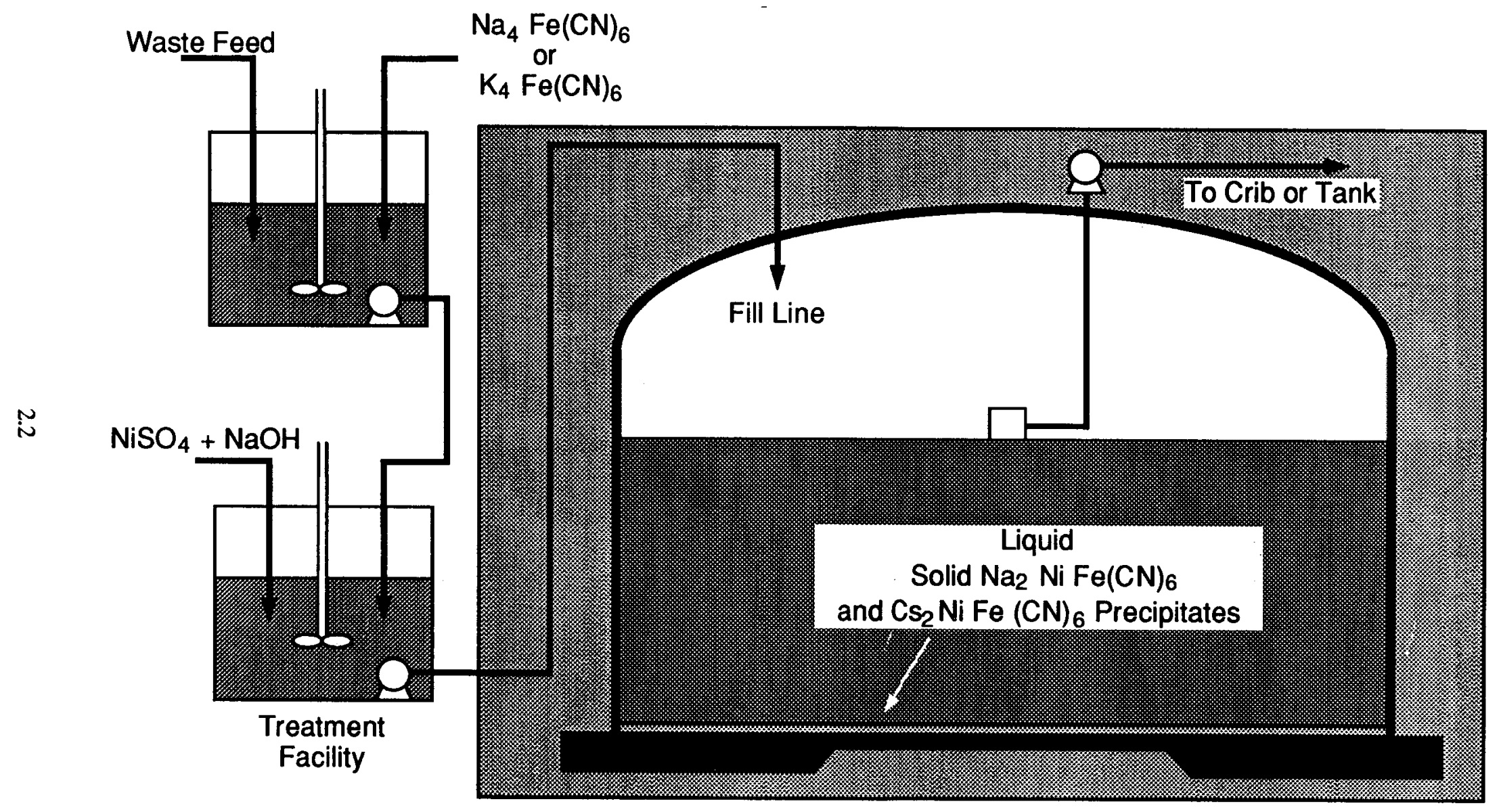

Figure 2.1. Ferrocyanide Scavening to Remove Cesium 
The overall goal of the Ferrocyanide Task Team efforts is to gain a thorough understanding of ferrocyanide tank waste and the reactive behavior of the constituents so that 1 ) the tanks can be maintained in a safe condition with minimal risk of an explosion, 2) one or more strategies can be selected to implement interim stabilization, and 3) ultimate disposal options can be identified.

The objective of the PNL work is to determine the conditions necessary for the ferrocyanide-bearing wastes in Hanford SSTs to represent a hazard, to determine the conditions where these same wastes are not a hazard, or to determine the conditions necessary to assure that the wastes are safe prior to treatment for permanent disposal. This work is a continuation of earlier studies performed by PNL and Los Alamos National Laboratory (LANL) (Burger and Scheele 1988; 1991). 


\subsection{Results of Past Studies}

Several reactions can be postulated for the oxidation of alkali metal nickel ferrocyanide by nitrate and nitrite. Simple reactions with nitrate and nitrite salts are illustrated for the cesium compound below. Other postulated reactions produce $\mathrm{CO}, \mathrm{N}_{2} \mathrm{O}, \mathrm{NO}, \mathrm{NO}_{2}$, carbonates, and hydroxides.

$$
\begin{aligned}
& \mathrm{Cs}_{2} \mathrm{NiFe}(\mathrm{CN})_{6}+6 \mathrm{NaNO}_{3}-\mathrm{Cs}_{2} \mathrm{O}+3 \mathrm{Na}_{2} \mathrm{O}+\mathrm{NiO}+\mathrm{FeO}+6 \mathrm{CO}_{2}+6 \mathrm{~N}_{2} \\
& \mathrm{Cs}_{2} \mathrm{NiFe}(\mathrm{CN})_{6}+10 \mathrm{NaNO}_{3}-\mathrm{Cs}_{2} \mathrm{O}+5 \mathrm{Na}_{2} \mathrm{O}+\mathrm{NiO}+\mathrm{FeO}+6 \mathrm{CO}_{2}+6 \mathrm{~N}_{2}
\end{aligned}
$$

The calculated enthalpies of reaction for Reactions (1) and (2) are -1655 and $-1704 \mathrm{~kJ} / \mathrm{mol}$, respectively. An uncertainty of $\pm 300 \mathrm{~kJ} / \mathrm{mol}$ is assumed based on the estimated heat of formation of cesium nickel ferrocyanide of $0 \pm 300 \mathrm{~kJ} / \mathrm{mol}$. The latter value is estimated from National Bureau of Standards $^{(a)}$ (Wagman et al. 1982) data for a number of metal ferrocyanides that have heats of formation $\left(\Delta \mathrm{H}_{\mathrm{f}}\right)$ ranging from about $-99 \mathrm{~kJ} / \mathrm{mol} \mathrm{CN}^{-}$to $+115 \mathrm{~kJ} / \mathrm{mol} \mathrm{CN}^{-}$, and others with free energies of formation from -2 to $+10 \mathrm{~kJ} / \mathrm{mol} \mathrm{CN}$. Using $0 \mathrm{~kJ} / \mathrm{mol}$ for $\Delta \mathrm{H}_{\mathrm{f}}$ for ferrocyanide, the heats of reaction for several reactions are given in Table 3.1.

In late 1988, PNL began an experimental program at the request of WHC to investigate the effects of temperature on the oxidation reaction between synthetic ferrocyanide and nitrates/nitrites representative of materials present in some of the Hanford SSTs. PNL used differential scanning calorimetry (DSC), scanning thermogravimetry (STG), and small-scale $(<100 \mathrm{mg}$ ) time-to-explosion (TTX) tests to investigate the relative effects of the oxidant melting point, the nitrate-to-nitrite ratio, the oxidant-to-ferrocyanide ratio, and several potential catalysts and/or initiators on the observed minimum reaction and explosion temperatures. In conjunction with PNL, LANL performed a series of tests to determine the sensitivity of one mixture of ferrocyanide and oxidant to initiation by impact, spark, friction, increased temperature, and increasing mass.

Table 3.1. Heats of Reaction for Different Oxidation Reactions

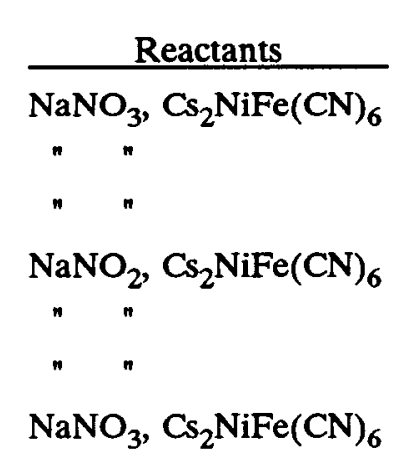

\begin{tabular}{c} 
Products \\
\hline $\mathrm{FeO}, \mathrm{NiO}, \mathrm{CO}_{2}, \mathrm{~N}_{2}$, and $\mathrm{NaCs}$ hydroxides \\
$" n$
\end{tabular}

Enthalpy,

\begin{tabular}{c}
$\mathrm{kJ} / \mathrm{mol}$ \\
\hline-2490 \\
-3025 \\
-2088 \\
-2925 \\
-3719 \\
-1704 \\
+624
\end{tabular}

(a) Now National Institute for Standards and Technology. 
The DSC, STG, and TTX methods showed that the oxidation pathway for oxidant mixtures containing both nitrate and nitrite is not simple. In the TTX, even after slow degradation at a low temperature (about $250^{\circ} \mathrm{C}$ ), the ferrocyanide and oxidant mixtures exploded when heated to $360^{\circ} \mathrm{C}$ to $400^{\circ} \mathrm{C}$. In addition, the characteristic brown color of $\mathrm{NO}_{2}$ was visually observed above the heated mixture prior to exploding.

The testing conducted at LANL showed that a mixture made from nearly stoichiometric amounts of cesium nickel ferrocyanide and oxidant, $50 \mathrm{~mol} \%$ sodium nitrate and $50 \mathrm{~mol} \%$ sodium nitrite, was insensitive both to reaction initiation in impact and friction tests and to a spark with energy equivalent to a static discharge from a human (Scheele and Cady 1992).

Earlier studies with the cesium salt indicated that both the reaction and explosion can be thermally initiated; are sensitive to the cation of the nitrate and/or nitrite; are sensitive to whether the oxidant is nitrate or nitrite; and are sensitive to tetrasodium ethylenediaminetetraacetate (EDTA), iron hydroxide, and nickel hydroxide catalysts or initiators. The lowest observed reaction, using DSC and STG, and explosion temperatures, using PNL's TTX test, for cesium nickel ferrocyanide were $220^{\circ} \mathrm{C}$ and $280^{\circ} \mathrm{C}$, respectively, for an equal molar oxidant mixture of sodium nitrate and sodium nitrite with 5 mol\% EDTA added (Burger and Scheele 1991).

These preliminary studies investigated the reactivity of cesium nickel ferrocyanide. The goal of the PNL Ferrocyanide Safety Project is to expand the scope of the original studies to include other compounds which may be present in the ferrocyanide tanks. 


\subsection{Ferrocyanide Safety Studies}

In October 1990 the Defense Nuclear Facilities Safety Board issued Recommendation 90-7 addressing safety issues of concern for Hanford waste tanks containing ferrocyanide compounds (DNFSB 1990).

The DNFSB Recommendation 90-7.5 states, in part, "The study should be extended to other metallic compounds of ferrocyanide that are known or believed to be present in the tanks, so that conclusions can be generalized as to the range of temperature and other properties needed for a rapid chemical reaction with sodium nitrate."

In response to this recommendation, the PNL studies were extended to metallic compounds of ferrocyanides other than cesium, in particular the sodium salts. Scavenging flowsheets were reproduced in the laboratory on synthetic waste mixtures. The resulting precipitates were characterized to determine species expected to be present in the tanks. A variety of thermal analyses were performed on the simulated ferrocyanide waste to determine the onset and energetics of the exothermic reactions.

\subsection{Preparation and Characterization of Simulated Ferrocyanide-Containing Wastes}

The purpose of this task is to prepare and characterize a wide variety of ferrocyanide and ferricyanide compounds that could exist in Hanford SSTs.

\subsubsection{Work Accomplished}

The compounds of primary interest include sodium nickel ferrocyanide; dinickel ferrocyanide; sodium nickel ferricyanide; and mixed salts of the sodium, potassium, and cesium nickel ferro- and ferricyanides. In addition to preparing the pure compounds, variations of actual flowsheets used in the tank farm scavenging campaigns were followed to prepare appropriate ferro- and ferricyanide compounds and waste mixtures. These compounds and mixtures were analyzed by a variety of techniques such as inductively coupled argon plasma/atomic emission spectroscopy (ICP/AES), ion chromatography (IC), total cyanide (CN) analysis, environmental scanning electron microscopy (ESEM), $x$-ray diffraction spectroscopy (XRD), DSC, STG, and TTX.

During FY 1991 attempts were made to prepare and characterize pure compounds of $\mathrm{Ni}_{2} \mathrm{Fe}(\mathrm{CN})_{6}$, $\mathrm{Na}_{2} \mathrm{NiFe}(\mathrm{CN})_{6}, \mathrm{~K}_{2} \mathrm{NiFe}(\mathrm{CN})_{6}, \mathrm{NaNiFe}(\mathrm{CN})_{6}$, and mixed salts of these ferro- and ferricyanide complexes from solutions representative of the In-Farm Flowsheet. One synthetic ferrocyanide waste was prepared using the In-Farm Flowsheet, allowing the solids to settle, and not washing these solids. Table 4.1 lists the planned target compounds and the concentrations of the reactants added in the preparation. This table also provides information on two vendor-prepared materials which were evaluated in some of the reactivity studies. These vendor compounds are identified as samples Ni-5 and FECN-11.

As discussed in Section 2.0, two primary flowsheets (U-Plant and In-Farm) produced the bulk of the ferrocyanide wastes in the tanks. Table 4.2 lists the compositions of the parent solutions treated and the concentrations of the ferrocyanide and nickel sulfate added to prepare the synthetic U-Plant and In-Farm Flowsheet wastes tested during FY 1991. PNL prepared four materials using the In-Farm Flowsheet, and WHC prepared one using the U-Plant Flowsheet and provided a sample to PNL for characterization. 
Table 4.1. Ferro- and Ferricyanide Preparation Method

Solid Formers, M

Parent Solution, $\mathbf{M}$

$\underline{\text { Sample \# }}$

Target Composition

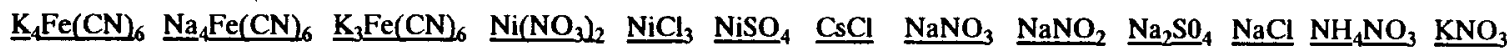

\begin{tabular}{|c|c|}
\hline $\mathrm{Ni}-\mathbf{1}$ & $\mathrm{Ni}_{2} \mathrm{Fe}(\mathrm{CN})_{6}$ \\
\hline $\mathrm{Ni-2}{ }^{(a)}$ & $\mathrm{Ni}_{2} \mathrm{Fe}(\mathrm{CN})_{6}$ \\
\hline $\mathrm{Ni}-3^{(b)}$ & $\mathrm{Ni}_{2} \mathrm{Fe}(\mathrm{CN})_{6}$ \\
\hline $\mathrm{Ni}-4$ & $\mathrm{Ni}_{2} \mathrm{Fe}(\mathrm{CN})_{6}$ \\
\hline $\mathrm{Ni}-5^{(c)}$ & $\mathrm{Ni}_{2} \mathrm{Fe}(\mathrm{CN})_{6}$ \\
\hline FECN-11 ${ }^{(c)}$ & $\mathrm{Na}_{2} \mathrm{Fe}(\mathrm{CN})_{5} \mathrm{NO} \cdot 2 \mathrm{H}_{2} \mathrm{O}$ \\
\hline FECN-13 & $\mathrm{Cs}_{2} \mathrm{NiFe}(\mathrm{CN})_{6}$ \\
\hline FECN-14 & $\mathrm{Cs}_{2} \mathrm{NiFe}(\mathrm{CN})_{6}$ \\
\hline FECN-15 & $\mathrm{Cs}_{2} \mathrm{NiFe}(\mathrm{CN})_{6}$ \\
\hline FECN-16 & $\mathrm{Na}_{2} \mathrm{NiFe}(\mathrm{CN})_{6}$ \\
\hline FECN-17 & $\mathrm{Na}_{2} \mathrm{NiFe}(\mathrm{CN})_{6}$ \\
\hline FECN-18 & $\mathrm{Na}_{2} \mathrm{NiFe}(\mathrm{CN})_{6}$ \\
\hline FECN-19 & $\mathrm{Na}_{2} \mathrm{NiFe}(\mathrm{CN})_{6}{ }^{(\mathrm{d})}$ (In-Farm) \\
\hline FECN-20 & $(\mathrm{Na} / \mathrm{K}) \mathrm{NiFe}(\mathrm{CN})_{6}{ }^{(\mathrm{d})}(\mathrm{In}-\mathrm{Farm})$ \\
\hline FECN-21 & $\mathrm{Na}_{2} \mathrm{NiFe}(\mathrm{CN})_{6}{ }^{(e)}(\mathrm{In}-\mathrm{Farm})$ \\
\hline FECN-22 & $\mathrm{K}_{2} \mathrm{NiFe}(\mathrm{CN})_{6}$ \\
\hline FECN-23 & $\mathrm{NaNiFe}(\mathrm{CN})_{6}$ \\
\hline FECN-24 & $\mathrm{Na}_{2} \mathrm{NiFe}(\mathrm{CN})_{6}$ \\
\hline FECN-25 & $\mathrm{Na}_{2} \mathrm{NiFe}(\mathrm{CN})_{6}$ \\
\hline FECN-26 & $\mathrm{Na}_{2} \mathrm{NiFe}(\mathrm{CN})_{6}$ (In-Farm) \\
\hline FECN-27 & $\mathrm{Na}_{2} \mathrm{NiFe}(\mathrm{CN})_{6}$ \\
\hline FECN-28 & $\mathrm{Na}_{2} \mathrm{NiFe}(\mathrm{CN})_{6}$ \\
\hline FECN-29 & $\operatorname{NaNiFe}(\mathrm{CN})_{6}$ \\
\hline
\end{tabular}

0.5

0.5

0.5

0.05

0.051

0.4

0.025

0.04

0.02

0.005

0.005

0.005

0.11

0.41
0.5

0.5

0.5

0.16

$\begin{array}{lll} & 0.05 & 0.2 \\ 0.05 & 0.2 \\ 0.4 & 1\end{array}$

0.025

0.04

0.02

0.09

0.025

0.025

0.07

0.1

0.05

0.005

0.2
0.005

0.005

0.005

$\begin{array}{llllll} & 5 & & & & \\ & 5 & & & & \\ & 5 & & & & \\ 0.005 & 4 & 2 & 0.2 & 0.003 & 0.05 \\ 0.005 & 4 & 2 & 0.2 & 0.003 & 0.05 \\ 0.005 & 4 & 2 & 0.2 & 0.003 & 0.05\end{array}$

(a) Solids washed with dilute $\mathrm{HNO}_{3}$.

(b) Solids washed with dilute $\mathrm{NaOH}$.

(c) Vendor supplied.

(d) Centrifuged and washed twice with $\mathrm{H}_{2} \mathrm{O}$.

(e) Settled. 
Table 4.2. Two Nominal Ferrocyanide Scavenging Flowsheets

\begin{tabular}{|c|c|c|}
\hline \multirow[b]{2}{*}{ Constituent } & \multicolumn{2}{|c|}{ Concentration, $\underline{\mathrm{M}}$} \\
\hline & U-Plant & In-Farm \\
\hline $\mathrm{Na}_{2} \mathrm{SO}_{4}$ & 0.02 & 0.2 \\
\hline $\mathrm{Na}_{3} \mathrm{PO}_{4}$ & 0.15 & \\
\hline $\mathrm{NaNO}_{3}$ & $3.72^{(a)}$ & 4.0 \\
\hline $\mathrm{NaNO}_{2}$ & & $2.0^{(\mathrm{b})}$ \\
\hline $\mathrm{NH}_{2} \mathrm{SO}_{3} \mathrm{H}$ & 0.034 & \\
\hline $\mathrm{Fe}\left(\mathrm{NH}_{4}\right)_{2}\left(\mathrm{SO}_{4}\right)_{2}$ & 0.017 & \\
\hline $\mathrm{Na}_{4} \mathrm{Fe}(\mathrm{CN})_{6}$ & 0.0025 & 0.005 \\
\hline $\mathrm{Sr}\left(\mathrm{NO}_{3}\right)_{2}$ & 0.004 & \\
\hline $\mathrm{NiSO}_{4}$ & 0.0025 & 0.005 \\
\hline $\mathrm{NH}_{4} \mathrm{NO}_{3}$ & & 0.05 \\
\hline $\mathrm{pH}$ & 9.5 & 9.5 \\
\hline
\end{tabular}

The materials prepared using the In-Farm supernate are identified as FECN-19, -20, and -21 . The FECN-19 and FECN-20 samples were prepared using sodium and potassium ferrocyanide, respectively, centrifuged and washed twice with deionized water, and dried at $110^{\circ} \mathrm{C}$. FECN-21 was prepared with sodium ferrocyanide, allowed to settle, the supernate decanted, and the solids dried at $110^{\circ} \mathrm{C}$. FECN-21 should be representative of wastes resulting from one variation of the In-Farm Flowsheet. FECN-21 contained 36 wt\% ferrocyanide as $\mathrm{Na}_{2} \mathrm{NiFe}(\mathrm{CN})_{6}$.

WHC provided PNL with two ferrocyanide materials. The first was a synthetic U-Plant waste prepared by adding sodium ferrocyanide to the acidic waste solution presented in Table 4.2. The pH was adjusted using sodium hydroxide to produce a basic solution of $\mathrm{pH} 9.5$; the nickel sulfate was added to form the insoluble alkali nickel ferrocyanide, and the solids were settled for 10 days. This 10-day settled solids slurry was characterized by PNL as a representative U-Plant ferrocyanide-bearing waste. For sample tracking and reporting purposes, this synthetic U-Plant waste was designated as WHC-1. While the WHC-1 was being stored, before the characterization studies began, additional solids settling occurred. We resuspended the solids by stirring, and dried an aliquot at $110^{\circ} \mathrm{C}$. The second material was produced by a commercial vendor and was identified as WHC-2.

Because WHC has scheduled a detailed chemical analysis of this material, our chemical analyses were limited to total carbon content. Based on the carbon analysis, the ferrocyanide concentration in WHC-1 was $1.7 \mathrm{wt} \%$ and assumed to be $\mathrm{Na}_{2} \mathrm{NiFe}(\mathrm{CN})_{6}$. 
The parent solutions shown in Table 4.1 and various washes were used to prepare pure ferrocyanide compounds representative of those precipitated during the cesium scavenging campaigns and to provide adequate supplies of potential ferrocyanide precipitates for investigating the parameters affecting ferrocyanide reactivity.

Once a pure compound was prepared, it was washed with distilled and/or deionized water and then either centrifuged or allowed to settle. Separation of the solid and liquid phases was sometimes difficult due to colloidal suspensions; therefore, various soluble compounds were added to destroy the colloid and allow separation of the two phases. Table 4.3 shows the washing methods, the number of water washes, the additives included to destroy the colloidal suspensions, and the separation techniques.

Table 4.3. Ferro- and Ferricyanide Washing Methods

\begin{tabular}{|c|c|c|c|c|}
\hline Target Composition & $\begin{array}{l}\text { Sample } \\
\text { Number }\end{array}$ & $\begin{array}{c}\text { No. of Water } \\
\text { Washes }\end{array}$ & $\begin{array}{l}\text { Method of } \\
\text { Separation }\end{array}$ & Additives (washes) \\
\hline $\mathrm{Ni}_{2} \mathrm{Fe}(\mathrm{CN})_{6}$ & $\mathrm{Ni}-1$ & 2 & Centrifuged & \\
\hline $\mathrm{Ni}_{2} \mathrm{Fe}(\mathrm{CN})_{6}$ & $\mathrm{Ni}-2$ & 2 & Filtered & $\mathrm{HNO}_{3}$ \\
\hline $\mathrm{Ni}_{2} \mathrm{Fe}(\mathrm{CN})_{6}$ & $\mathrm{Ni}-3$ & 2 & Filtered & $\mathrm{NaOH}$ \\
\hline $\mathrm{Ni}_{2} \mathrm{Fe}(\mathrm{CN})_{6}$ & $\mathrm{Ni}-4$ & 2 & Centrifuged & \\
\hline $\mathrm{Ni}_{2} \mathrm{Fe}(\mathrm{CN})_{6}{ }^{(\mathrm{a})}$ & $\mathrm{Ni}-5$ & 0 & & \\
\hline $\mathrm{Na}_{2} \mathrm{Fe}(\mathrm{CN})_{5} \mathrm{NO} \cdot 2 \mathrm{H}_{2} \mathrm{O}^{(\mathrm{a})}$ & FECN-11 & 0 & & \\
\hline $\mathrm{Cs}_{2} \mathrm{NiFe}(\mathrm{CN})_{6}$ & FECN-13 & 0 & Centrifuged & \\
\hline $\mathrm{Cs}_{2} \mathrm{NiFe}(\mathrm{CN})_{6}$ & FECN-14 & 2 & Centrifuged & \\
\hline $\mathrm{Cs}_{2} \mathrm{NiFe}(\mathrm{CN})_{6}$ & FECN-15 & 2 & Centrifuged & \\
\hline $\mathrm{Na}_{2} \mathrm{NiFe}(\mathrm{CN})_{6}$ & FECN-16 & 3 & Centrifuged & \\
\hline $\mathrm{Na}_{2} \mathrm{NiFe}(\mathrm{CN})_{6}$ & FECN-17 & 3 & Centrifuged & \\
\hline $\mathrm{Na}_{2} \mathrm{NiFe}(\mathrm{CN})_{6}$ & FECN-18 & 2 & Centrifuged & \\
\hline $\mathrm{Na}_{2} \mathrm{NiFe}(\mathrm{CN})_{6}$ & FECN-19 & 2 & Centrifuged & $\mathrm{NaOH}$ \\
\hline$(\mathrm{Na} / \mathrm{K}) \mathrm{NiFe}(\mathrm{CN})_{6}$ & FECN-20 & 2 & Centrifuged & $\mathrm{NaOH}$ \\
\hline In-Farm & FECN-21 & 0 & Settled & \\
\hline $\mathrm{K}_{2} \mathrm{NiFe}(\mathrm{CN})_{6}$ & FECN-22 & 3 & Centrifuged & \\
\hline $\mathrm{NaNiFe}(\mathrm{CN})_{6}$ & FECN-23 & 3 & Centrifuged & \\
\hline $\mathrm{Na}_{2} \mathrm{NiFe}(\mathrm{CN})_{6}$ & FECN-24 & 0 & Centrifuged & \\
\hline $\mathrm{Na}_{2} \mathrm{NiFe}(\mathrm{CN})_{6}$ & FECN-25 & 0 & Centrifuged & \\
\hline $\mathrm{Na}_{2} \mathrm{NiFe}(\mathrm{CN})_{6}$ & FECN-26 & 0 & Centrifuged & $\mathrm{NaCl}, \mathrm{HCl}, \mathrm{NaOH}$ \\
\hline In-Farm & FECN-27 & 0 & Centrifuged & \\
\hline $\mathrm{Na}_{2} \mathrm{NiFe}(\mathrm{CN})_{6}$ & FECN-28 & 0 & Centrifuged & Various \\
\hline $\mathrm{NaNiFe}(\mathrm{CN})_{6}$ & FECN-29 & 2 & Centrifuged & \\
\hline
\end{tabular}

(a) Commercially prepared. 
The compositions of some of the ferro- and ferricyanide solids and synthetic wastes were extensively characterized using the following techniques: ICP/AES, IC, total $\mathrm{CN}$, total organic carbon/total inorganic carbon/total carbon (TOC/TIC/TC) analysis, XRD, and ESEM. The calculated compositions of the analyzed ferro- and ferricyanides are given in Table 4.4.

The stoichiometry of these solids was determined by normalizing the concentrations of each element as obtained by ICP to the Fe concentration. When available, the XRD data were used to determine whether other compounds were present in the sample. If another compound was observed by XRD, then the concentration of that compound was determined by assuming that the ferrocyanide compound was stoichiometric and that any excess cation was present as the other compound observed in the XRD diffractogram. Limited IC was done on water leaches of the sample to determine the anion concentrations in the sample. These data were compared with the ICP data to give an appropriate estimate of the concentrations of the other compounds. The amount of water in the sample was estimated from the mass loss below nominally $200^{\circ} \mathrm{C}$ as measured by STG.

Table 4.4. Measured Compositions for Ferro- and Ferricyanide Solids ${ }^{(a)}$

\begin{tabular}{|c|c|}
\hline Sample No. & Analyzed Composition \\
\hline $\mathrm{Ni}-1$ & $\mathrm{NA}^{(\mathbf{b})}$ \\
\hline $\mathrm{Ni}-2$ & $\mathrm{~K}_{1.2} \mathrm{Ni}_{1.4} \mathrm{Fe}(\mathrm{CN})_{6} \cdot 2.3 \mathrm{H}_{2} \mathrm{O}+1.6 \mathrm{KNO}_{3}$ \\
\hline $\mathrm{Ni}-3$ & NA \\
\hline $\mathrm{Ni}-4$ & $\mathrm{Ni}_{2} \mathrm{Fe}(\mathrm{CN})_{6} \cdot 5.4 \mathrm{H}_{2} \mathrm{O}+1 \mathrm{NaNO}_{3}$ \\
\hline $\mathrm{Ni}-5$ & $\mathrm{Ni}_{2} \mathrm{Fe}(\mathrm{CN})_{6} \cdot 10 \mathrm{H}_{2} \mathrm{O}+0.4 \mathrm{Ni}(\mathrm{CN})_{2} \cdot 2 \mathrm{H}_{2} \mathrm{O}$ \\
\hline FECN-11 & $\mathrm{Na}_{2} \mathrm{Fe}(\mathrm{CN})_{5} \mathrm{NO} \cdot 2 \mathrm{H}_{2} \mathrm{O}$ \\
\hline FECN-13 & NA \\
\hline FECN-14 & $\mathrm{Na}_{0.2} \mathrm{~K}_{0.5} \mathrm{Cs}_{1.3} \mathrm{NiFe}(\mathrm{CN})_{6} \cdot 2 \mathrm{H}_{2} \mathrm{O}$ \\
\hline FECN-15 & NA \\
\hline FECN-16 & $\mathrm{Na}_{2} \mathrm{NiFe}(\mathrm{CN})_{6} \cdot 3 \mathrm{H}_{2} \mathrm{O}+1 \mathrm{NaNO}_{3}$ \\
\hline FECN-17 & $\mathrm{Na}_{2} \mathrm{NiFe}(\mathrm{CN})_{6} \cdot 3 \mathrm{H}_{2} \mathrm{O}+1 \mathrm{NaNO}_{3}$ \\
\hline FECN-19. & $\mathrm{Na}_{2} \mathrm{NiFe}(\mathrm{CN})_{6} \cdot 2.3 \mathrm{H}_{2} \mathrm{O}+1.6 \mathrm{NaNO}_{3}$ \\
\hline FECN-20 & $\mathrm{Na}_{2} \mathrm{NiFe}(\mathrm{CN})_{6} \cdot 2.4 \mathrm{H}_{2} \mathrm{O}+1.8 \mathrm{NaNO}_{3}$ \\
\hline FECN-21 & $\mathrm{Na}_{2} \mathrm{NiFe}(\mathrm{CN})_{6} \cdot 5.3 \mathrm{H}_{2} \mathrm{O}+4 \mathrm{NaNO}_{3} / 2 \mathrm{NaNO}_{2}$ \\
\hline FECN-22 & $\mathrm{K}_{2} \mathrm{NiFe}(\mathrm{CN})_{6} \cdot 1 \mathrm{H}_{2} \mathrm{O}+0.8 \mathrm{KNO}_{3}$ \\
\hline FECN-23 & $\mathrm{Na}_{0.6} \mathrm{Ni}_{1.2} \mathrm{Fe}(\mathrm{CN})_{6} \cdot 4.5 \mathrm{H}_{2} \mathrm{O}+1.1 \mathrm{NaNO}_{3}$ \\
\hline WHC-2 & $\mathrm{Na}_{2} \mathrm{NiFe}(\mathrm{CN})_{6} \cdot 4.5 \mathrm{H}_{2} \mathrm{O}+0.9 \mathrm{Na}_{2} \mathrm{SO}_{4}$ \\
\hline
\end{tabular}

(a) Compositions assume stability of ferro- and ferricyanide complexes.

(b) NA = Not analyzed. 
Figures 4.1 and 4.2 give examples of the data obtained for the ferrocyanides from XRD and ESEM, respectively. Samples of what is believed to be $\mathrm{Na}_{2} \mathrm{NiFe}(\mathrm{CN})_{6}, \mathrm{Ni}_{2} \mathrm{Fe}(\mathrm{CN})_{6}$, and $\mathrm{Cs}_{2} \mathrm{NiFe}(\mathrm{CN})_{6}$ were examined by XRD to identify the phases (as far as possible), determine impurities present, and compare the various phases. Diffraction data for $\mathrm{Na}_{2} \mathrm{NiFe}(\mathrm{CN})_{6}$ are not present in the ICDD (International Center for Diffraction Data ${ }^{(a)}$ ) database, so no direct comparison could be made for this compound. Data for the comparison of the potassium phase are available. Data for both $\mathrm{Cs}_{2} \mathrm{NiFe}(\mathrm{CN})_{6}$ and $\mathrm{Ni}_{2} \mathrm{Fe}(\mathrm{CN})_{6}$ are present in the database, and good matches with these patterns were obtained. Lattice parameters for $\mathrm{Na}_{2} \mathrm{NiFe}(\mathrm{CN})_{6}$ of $\mathrm{A}_{\mathrm{o}}=10.3 \AA$ were also calculated from the XRD data. Depending on the preparation and washing methods employed, slightly different compositions were observed. Modifications to the preparation and washing techniques were made to remove the $\mathrm{NaNO}_{3}$ from the ferrocyanide precipitate. Drying methods were also studied to obtain ferrocyanide compounds with limited amounts of $\mathrm{H}_{2} \mathrm{O}$.

\subsubsection{Conclusions}

These studies indicate that the likely ferrocyanide compound which precipitated from the In-Farm processing was sodium nickel ferrocyanide independent of the form of the added soluble ferrocyanide. When potassium ferrocyanide was used as the ferrocyanide source, the product was still sodium nickel ferrocyanide. This is not surprising considering the large excess of sodium ion in the solution; nominally a ratio of 1200:1 sodium to potassium. Of course in competition with the large sodium excess is the increased stability (lower solubilities) of the heavy alkali metal nickel ferrocyanides in order of increasing tendency to form a sparingly soluble ferrocyanide of $\mathrm{Li}<\mathrm{Na}<\mathrm{K}<\mathrm{Rb}<\mathrm{Cs}$ (Tananaev, Glushkova, and Seifer 1956; Shamaev, Chudnovskikh, and Pavlidi 1982).

In addition to the likelihood that $\mathrm{Na}_{2} \mathrm{NiFe}(\mathrm{CN})_{6}$ is the product of the In-Farm cesium scavenging, the nitrate and nitrite were found to be very difficult to remove from the solid ferrocyanide. Even washing twice with water failed to remove these soluble salts. To successfully remove the nitrate and nitrite from the ferrocyanide precipitate, other ionic solutions had to be used to provide the necessary ionic strength to separate the solids from the bulk of the aqueous solution.

Another significant finding was the presence of a near-stoichiometric amount of oxidant in the settled and unwashed solids from the In-Farm Flowsheet assuming the stoichiometrics given in Equations (1) and (2). Other flowsheet variations could introduce diluents and/or potential catalysts and initiators such as calcium phosphate or sulfide.

\subsubsection{Future Work}

Work for FY 1992 will involve preparing and characterizing additional synthetic wastes using other variations of the flowsheets. Among the variations to be tested are different ferrocyanide concentrations, adding the radiostrontium scavenging step, and adding the radiocobalt scavenging step. The concentration of ferrocyanide is of critical importance in assessing the reactivity of the ferrocyanide wastes. Another waste to be simulated is ferricyanide, which could be produced by scavenging using the U-Plant Flowsheet. The characterization of the synthetic ferro- and ferricyanide compounds and synthetic wastes will be completed.

(a) Formerly the JCPDS, Joint Committee on Powder Diffraction Standards. 


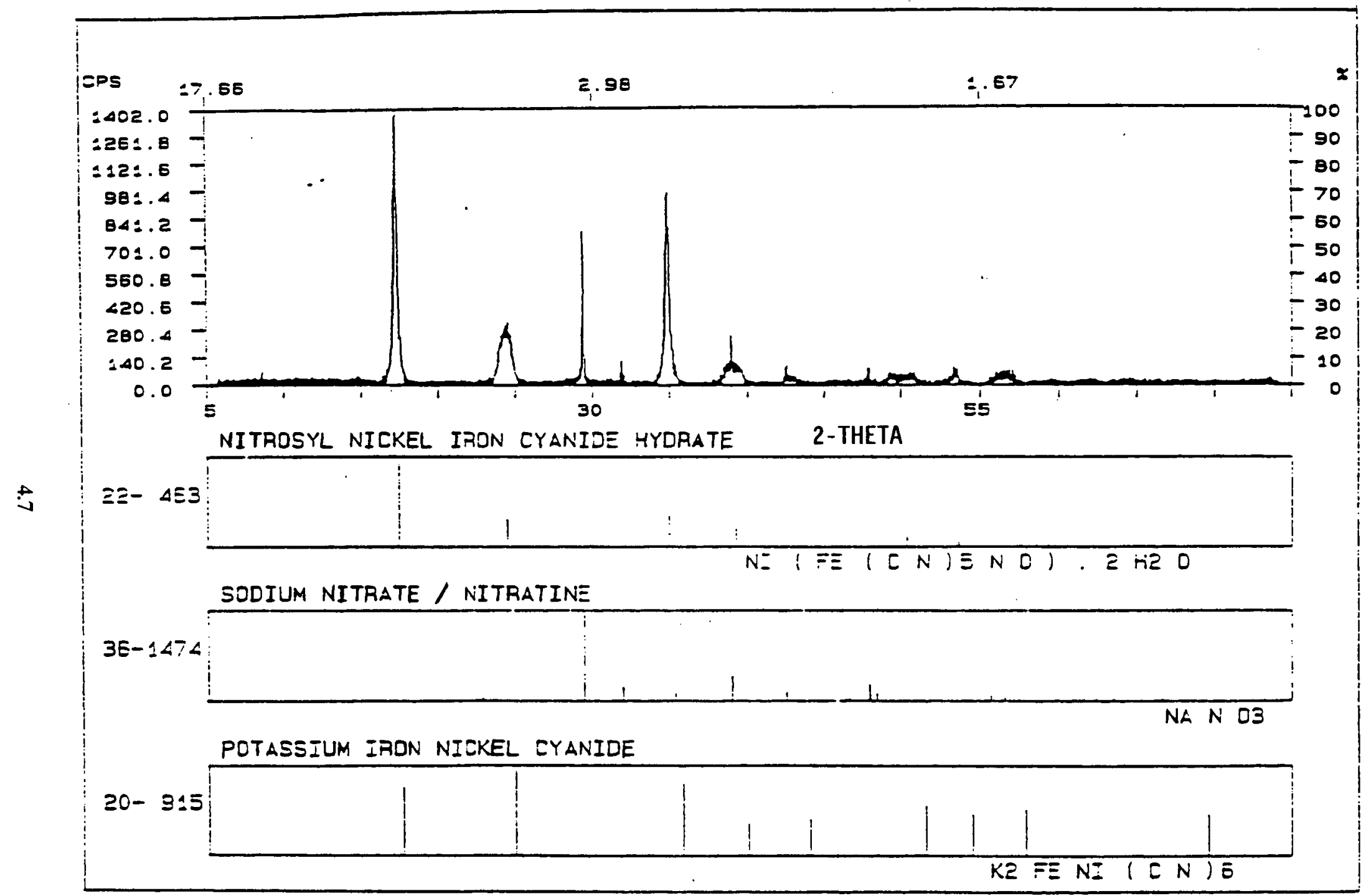

Figure 4.1. X-ray Diffraction Spectrum of the In-Farm Flowsheet Prepared Ferrocyanide (FECN-21) 

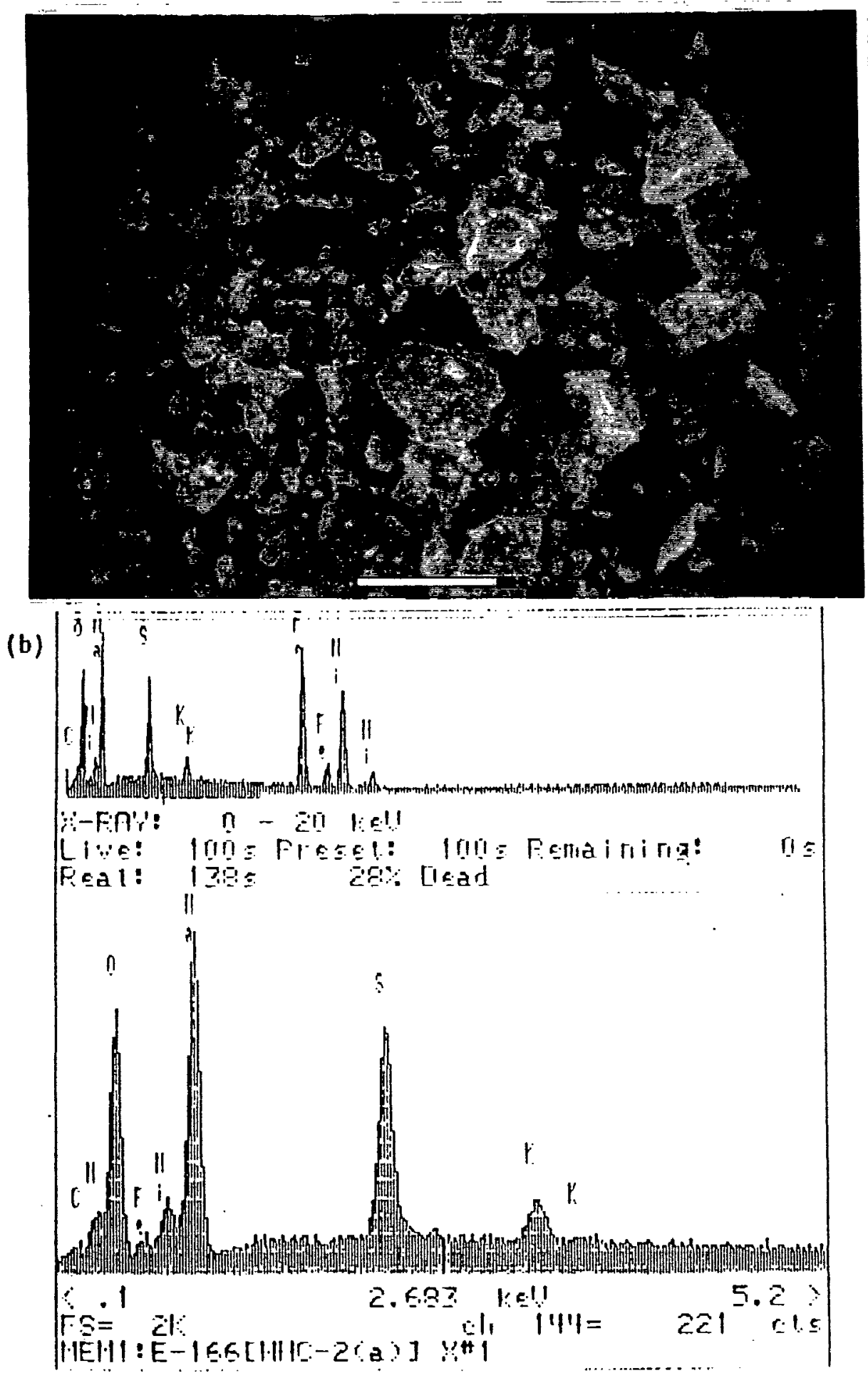

Figure 4.2. Environmental Scanning Electron Microscopy (ESEM) Data of WHC-2. Figure (a) is the picture taken by the ESEM, and figure (b) is the elements present in the particles. 
Physical characterization of the U-Plant and In-Farm Flowsheets will be conducted. The amount of water in the ferrocyanide solids will be measured. These data may be used as further indication of the safety of the ferrocyanide solids in the tanks. Selected rheological properties of the synthetic wastes will also be measured. These data are essential for designing retrieval and/or remediation processes for future cleanup activities.

\subsection{Chemical Nature of Iron and Cyanide in Wastes}

The efforts for this task concentrated on establishing techniques for the speciation of solid products to be used to conduct the aging studies and eventually for actual tank samples.

\subsubsection{Work Accomplished}

In FY 1991 the following activities were accomplished: useful tools for the analysis of solid ferrocyanide materials were identified; analytical methods for the speciation of these materials were developed; techniques for the determination of $\mathrm{Fe}(\mathrm{II})$ to $\mathrm{Fe}(\mathrm{III})$ ratios were investigated; techniques for the identifica. tion of nonferrocyanide iron-containing products were investigated; and a database of analytical and spectral data was compiled.

Techniques investigated this fiscal year that appear to be useful for analysis of solid ferrocyanide materials are infrared spectroscopy (IR); XRD; ESEM and energy dispersive spectroscopy (EDS); and carbon, hydrogen, nitrogen ( $\mathrm{CHN}$ ) elemental analyses. Mössbauer spectroscopy has been investigated to a limited extent and may prove to be of value, but further evaluation of the applicability of this technique is needed. Carbon-13 nuclear magnetic resonance (NMR) does not appear to be useful for ferrocyanide sample analysis. Figures 4.3 through 4.5 and Table 4.5 show the type of data collected and their use in speciation, using a $\mathrm{Na}_{2} \mathrm{NiFe}(\mathrm{CN})_{6}$ flowsheet material (FECN-21) as an example.

Figure 4.3 shows an IR absorption spectrum of FECN-21 dispersed in a $\mathrm{KBr}$ pellet. The intense band at $2080 \mathrm{~cm}^{-1}$ is the $\mathrm{CN}$ stretch from ferrocyanide. In ferricyanides, the position of the $\mathrm{CN}$ stretching absorption is shifted to higher frequencies. The IR spectrum of FECN-21 shows that $\mathrm{NO}_{3}{ }^{-}\left(1380 \mathrm{~cm}^{-1}\right)$, $\mathrm{NO}_{2}^{-}\left(1265 \mathrm{~cm}^{-1}\right)$, and $\mathrm{SO}_{4}^{-2}\left(1155,1115 \mathrm{~cm}^{-1}\right)$ anions are present. Phosphate would also have been detected $\left(1000\right.$ to $\left.1100 \mathrm{~cm}^{-1}\right)$ had it been present. Water appears at 3430 and $1600 \mathrm{~cm}^{-1}$. IR data have also been used to determine the $\mathrm{Fe}(\mathrm{CN})_{6}{ }^{4}-\mathrm{NO}_{3}{ }^{-}$ratio by comparing the areas of the cyanide and nitrate absorbances. However, for FECN-21 this was not possible because the nitrite band overlaps the nitrate band and an accurate nitrate area cannot be obtained.

Powder XRD (Figure 4.4) patterns show that crystalline $\mathrm{NaNO}_{3}$ and $\mathrm{NaNO}_{2}$ are in the sample. No sulfate salts are detected by this method. The sulfate is either not crystalline or is not present in high enough concentration to be observed. No reference spectrum for disodium nickel ferrocyanide was found in the XRD database, but the structure is very similar to other ferrocyanides. Peaks in the powder patterns tend to be broad for many samples, indicating noncrystallinity or mixtures of slightly different phases. Some batches of $\mathrm{Na}_{2} \mathrm{NiFe}(\mathrm{CN})_{6}$ showed slightly shifted peaks, which might arise from differing degrees of hydration.

The ESEM/EDS instrument was used for particle and elemental analyses. This instrument is capable of analyzing uncoated and unpolished samples and can detect elements as smail as boron. EDS (Figure 4.5) indicates that sulfur is present to a small extent in the particle analyzed. (Some particles contained much more than that shown; others contained less.) All of the other elements that were detected 


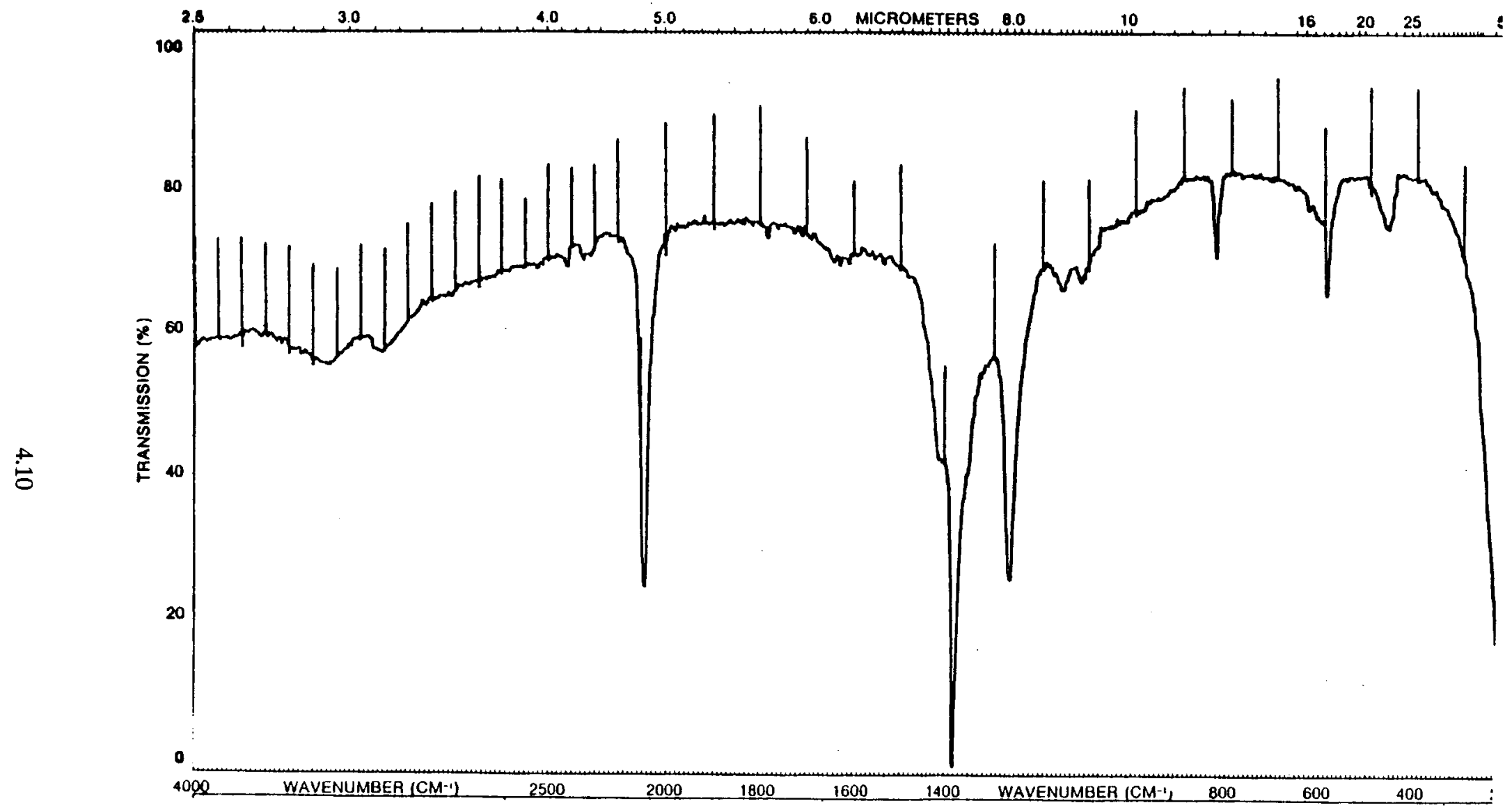

Figure 4.3. Infrared Spectrum (KBr Pellet) of FECN-21 [flowsheet-prepared $\mathrm{Na}_{2} \mathrm{NiFe}(\mathrm{CN})_{6}$ ] 


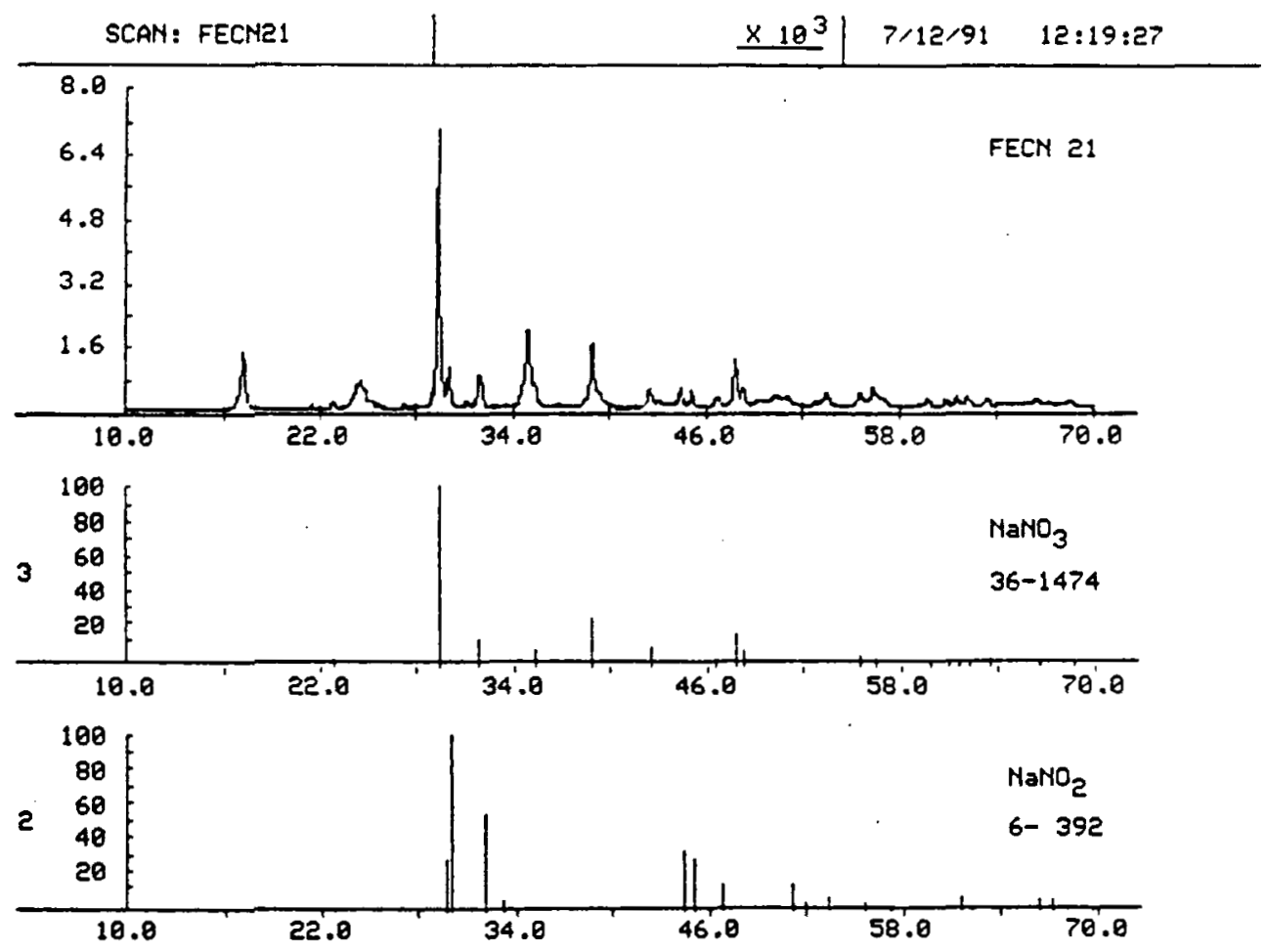

Figure 4.4. Powder X-ray Diffraction Results for FECN-21 [flowsheet-prepared $\mathrm{Na}_{2} \mathrm{NiFe}(\mathrm{CN})_{6}$ ]

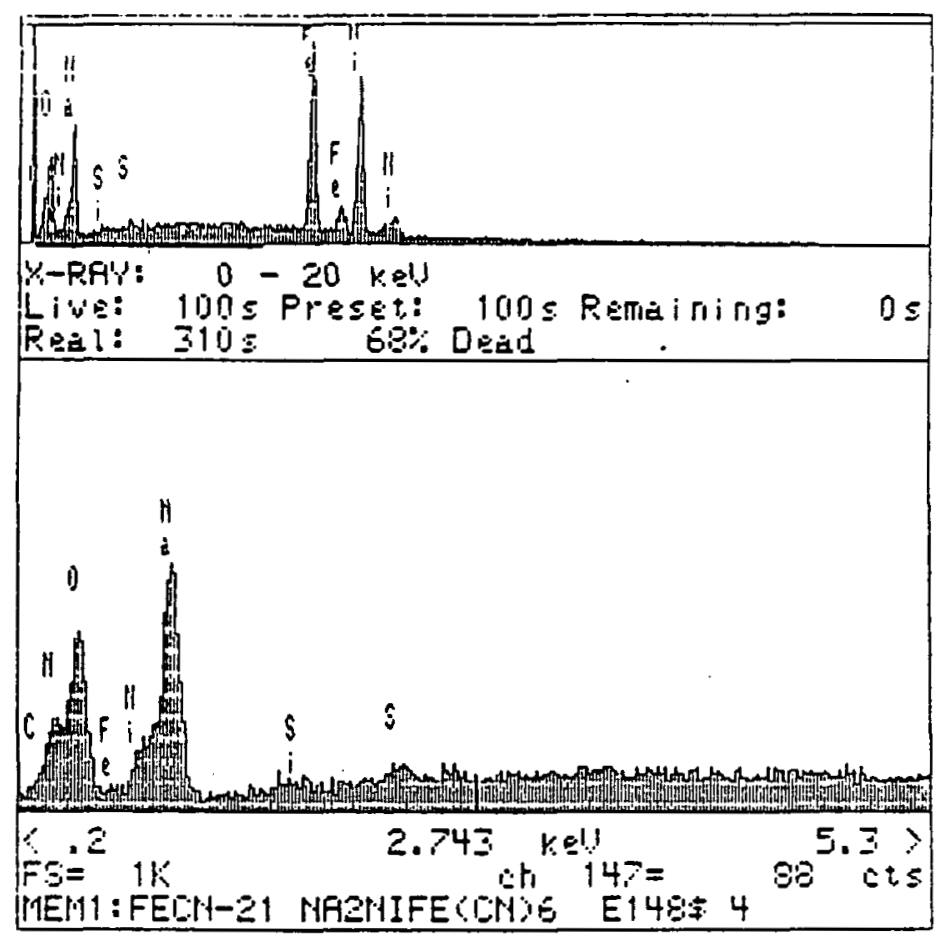

Figure 4.5. Energy Dispersive Spectroscopy Spectrum for FECN-21 [flowsheet-prepared $\mathrm{Na}_{2} \mathrm{NiFe}(\mathrm{CN})_{6}$ ] 
Table 4.5. Carbon, Hydrogen, Nitrogen Elemental Analyses Results for FECN-21, Flowsheet $\mathrm{Na}_{2} \mathrm{NiFe}(\mathrm{CN})_{6}$

\begin{tabular}{|c|c|c|c|}
\hline \multirow{3}{*}{ Experimental Results, wt\% } & $\mathrm{C}$ & $\mathrm{H}$ & $\mathbf{N}$ \\
\hline & 6.78 & 1.08 & 18.76 \\
\hline & 6.92 & 1.06 & 19.06 \\
\hline Experimental Average, wt\% & 6.85 & 1.07 & 18.91 \\
\hline $\begin{array}{l}\text { Theoretical Calculated for } \\
0.25 \mathrm{Na}_{2} \mathrm{NiFe}(\mathrm{CN})_{6} \cdot \mathrm{NaNO}_{3} \bullet \\
\mathrm{NaNO}_{2} \cdot 0.05 \mathrm{NiSO}_{4} \cdot 1.4 \mathrm{H}_{2} \mathrm{O}\end{array}$ & 6.77 & 1.06 & 18.42 \\
\hline Percent Deviation & 1.18 & 0.89 & 2.65 \\
\hline
\end{tabular}

are expected to be in the sample except $\mathrm{Si}$, which is in the instrument itself and is often observed in the background. Quantitation of each element by this technique has not proven consistent; a great deal of variability in peak heights was observed. Mounted, polished samples may give better results.

CHN elemental analyses, in combination with IR, XRD, and ESEMEDS data, are valuable for determining the nominal composition of the sample. In CHN analyses, the sample is combusted in pure oxygen at $900^{\circ} \mathrm{C}$. For this study burn times were optimized on known ferrocyanide samples, and reproducibility was very good for all samples. Reagent-grade sodium nitrate tended to analyze lower in nitrogen than that expected theoretically.

Compositions chosen were consistent with all analytical data and gave good agreement with $\mathrm{CHN}$ values. The nominal composition determined from these data for FECN-21 (Table 4.5) is 0.25 $\mathrm{Na}_{2} \mathrm{NiFe}(\mathrm{CN})_{6} \cdot \mathrm{NaNO}_{3} \cdot \mathrm{NaNO}_{2} \cdot 0.05 \mathrm{NiSO}_{4} \cdot 1.4 \mathrm{H}_{2} \mathrm{O}$. In similar fashion, compositions of several other ferrocyanide simulants were estimated. Table 4.6 summarizes these results.

Mössbauer spectroscopy has also been investigated as a tool to probe the chemical environment of iron in the ferrocyanide samples. To date, only purchased ferrocyanide and ferricyanide have been run in order to ensure that the instrument was working properly and to establish operational parameters. Figure 4.6 shows the Mössbauer spectrum and the associated deconvolution for a mixture of potassium ferroand ferricyanide. Synthetic materials will be investigated in FY 1992. This technique is not only expected to give information about the ferrocyanide or ferricyanide, but should also detect the presence of iron in forms other than ferrocyanide, such as hydroxides or oxides. This speciation information will be of value in the aging studies as well as for determining $\mathrm{Fe}(\mathrm{II}) / \mathrm{Fe}(\mathrm{III})$ ratios.

\subsubsection{Conclusions}

Useful techniques for the analysis of solid ferri- and ferrocyanide materials were identified. The techniques, which include IR, XRD, ESEM, EDS, and CHN elemental analyses, give complementary speciation data. Molecular information is obtained for crystalline components from XRD data; elemental information is gained from EDS and CHN; and IR gives functional group data. Data were used together to speciate several synthetic ferro- and ferricyanide materials. A database of spectral and analytical data was 
Table 4.6. Nominal Compositions of Synthetic Ferrocyanide Materials

Sample ID
FECN-16, $\mathrm{Na}_{2} \mathrm{NiFe}(\mathrm{CN})_{6}$
FECN-19, $\mathrm{Na}_{2} \mathrm{NiFe}(\mathrm{CN})_{6}$
FECN-17, $\mathrm{Na}_{2} \mathrm{NiFe}(\mathrm{CN})_{6}$
FECN-18, $\mathrm{Na}_{2} \mathrm{NiFe}(\mathrm{CN})_{6}$
$\mathrm{Ni-4}, \mathrm{Ni}_{2} \mathrm{Fe}(\mathrm{CN})_{6}$
FECN-14, $\mathrm{Cs}_{2} \mathrm{NiFe}(\mathrm{CN})_{6}$
FECN-20, $(\mathrm{K}-\mathrm{Na}) \mathrm{NiFe}(\mathrm{CN})_{6}$
FECN-21, flowsheet $\mathrm{Na}{ }_{2} \mathrm{NiFe}(\mathrm{CN})_{6}$
FECN-22, $\mathrm{K}_{2} \mathrm{NiFe}(\mathrm{CN})_{6}$
FECN-23, NaNiFe(CN $)_{6}$
FECN-28b, Na ${ }_{2} \mathrm{NiFe}(\mathrm{CN})_{6}$
WHC-1, U-Plant Flowsheet

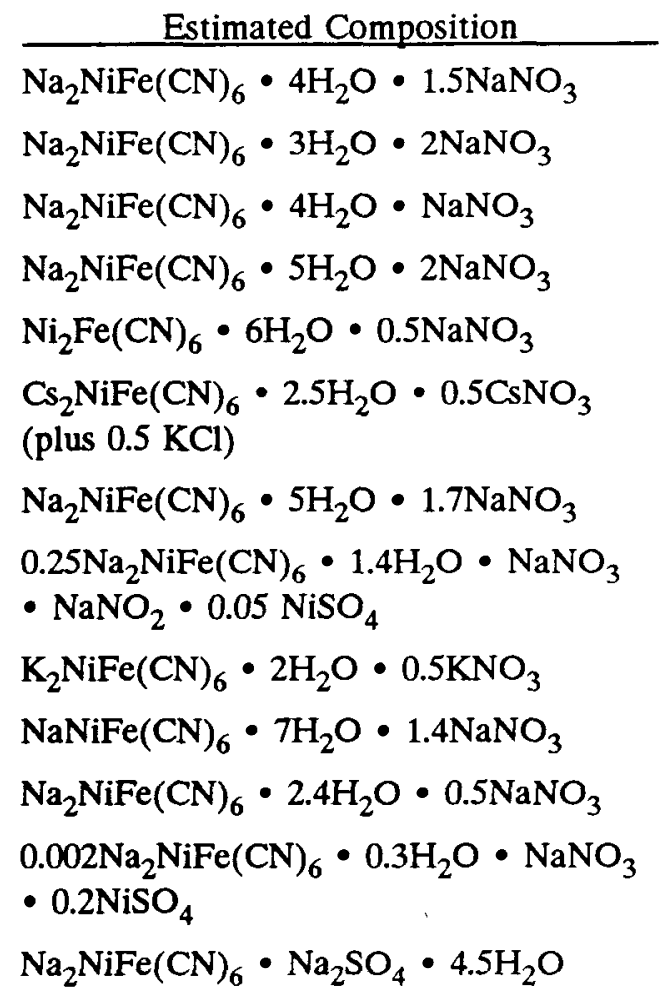

compiled. The use of Mössbauer spectroscopy to determine $\mathrm{Fe}(\mathrm{II}) / \mathrm{Fe}(\mathrm{III})$ ratios and for detecting nonferrocyanide iron-containing compounds requires further study. Carbon-13 NMR does not appear to be a generally useful characterization tool.

\subsubsection{Future Work}

Aging processes will be studied by performing gamma radiolysis, chemical oxidation, and hydrolysis/ metathesis in highly alkaline solutions. Methods to follow aging reactions have been determined, but the ferrocyanide material to use, that which most closely simulates the in-tank material, has not been identified. Once this material is identified and becomes available, experimentation can be initiated.

Although several analytical tools show potential, a technique to determine $\mathrm{Fe}$ (II)/Fe(III) ratios in solid samples has not been established. Mössbauer spectroscopy may be able to give this information, but experiments have not been run. Electron spectroscopy for chemical analysis (ESCA) might also be used, but this method has not been explored. Infrared spectroscopy may be the most likely method to give the needed information. Cyanide stretching bands should be a sensitive indicator of oxidation state and chemical environment, and absorbances are intense. Similarly, Raman spectroscopy might also prove useful. 


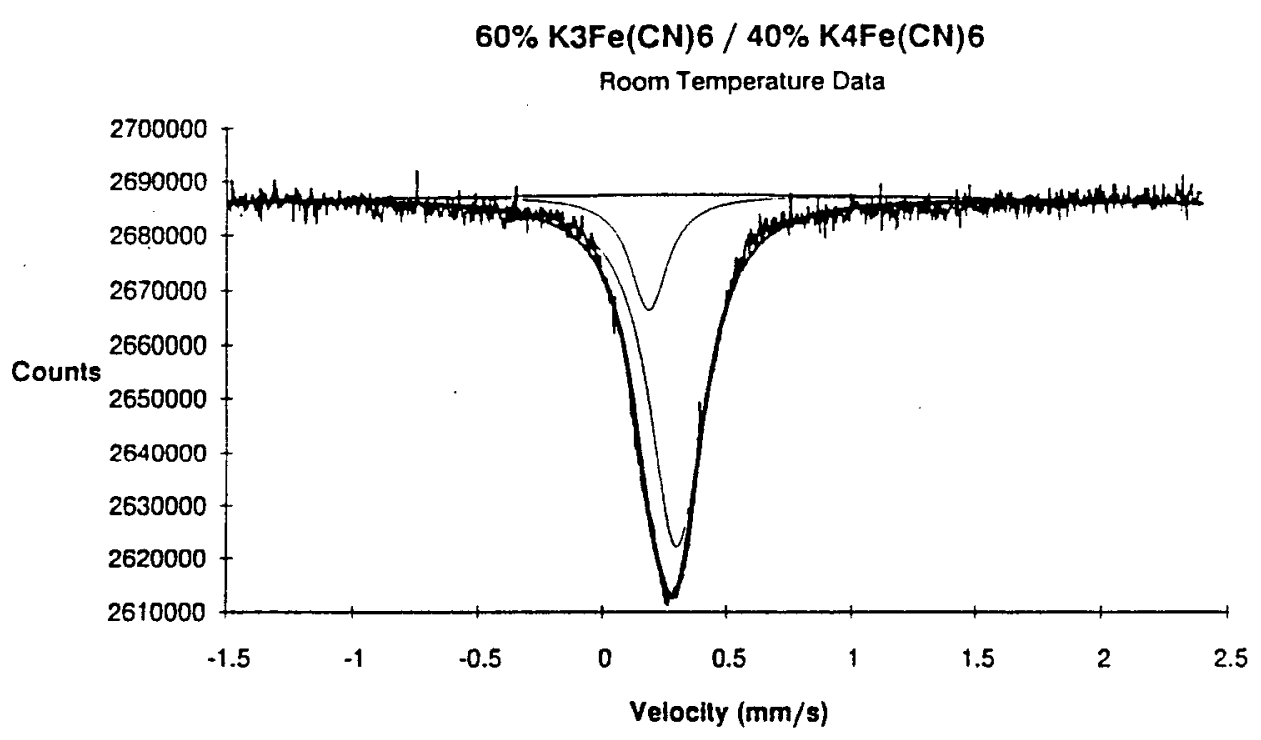

Figure 4.6. Mőssbauer Spectrum and Model Fit for $60 \% \mathrm{~K}_{3} \mathrm{Fe}(\mathrm{CN})_{6} / 40 \% \mathrm{~K}_{4} \mathrm{Fe}(\mathrm{CN})_{6}$

\subsection{Reaction Mechanisms and Kinetics}

The scope of this task is to monitor reactions by examining gaseous and solid products from the thermal reaction of ferrocyanide materials with nitrate/nitrite mixtures.

\subsubsection{Work Accomplished}

The FY 1991 accomplishments included the following activities: procurement and installation of a new data acquisition system for an existing quadruple mass spectrometer (MS); interface of the MS to an existing analytical pyrolysis unit; design and construction of a temperature-programmable microfurnace; interface of the microfurnace to the MS; and obtaining results from the temperature-programmed decomposition of flowsheet ferrocyanides. Discussions were held with Dr. William Thomson of Washington State University on the use of Dynamic XRD (DXRD) to follow the thermal reaction of ferrocyanide solids. Initial scoping studies indicate the changes can be detected in the reacting solids as a function of temperature.

An existing Hewlett-Packard Model 5970 Mass Selective Detector, which was part of a bench-top gas chromatograph-mass spectrometer (GC-MS), was available to monitor gases produced by the thermal decomposition of the synthetic ferrocyanide wastes. The major drawback of the MS for use as a gas monitor was the outdated data acquisition system. For gas analyses during the temperature decomposition of ferrocyanides, more than 3000 data points are acquired over mass range of 10 to $150 \mathrm{amu}$. The old system only allows data to be collected down to $15 \mathrm{amu}$, whereas the new system can go below $10 \mathrm{amu}$. Hardware and software were procured and installed to upgrade the system to a PC-based system, IBM-compatible $33 \mathrm{Mhz} 386$ computer. The new system performs data acquisition, analyses, and output not capable on the old system.

The MS was equipped with a GC interface known as an open-split interface. This interface requires sample introduction by a pressurized gas flow. An alternate interface known as the direct interface relies upon the vacuum in the MS source to draw a sample into the source. The current interface could not be 
used directly with the STG or DSC, and a different piece of equipment was required to thermally decompose ferrocyanide samples. The only equipment available in our laboratory that could be used directly was a Chemical Data Systems Model 100 Pyroprobe, which is used for analytical pyrolyses and is designed to interface directly to a GC or GC-MS. Two sample probes are available for this system, a platinum foil for samples under $1 \mathrm{mg}$ and a platinum wire coil for samples from 1 to $25 \mathrm{mg}$. For the coil probe, the sample is placed in a quartz tube held in place by quartz wool and weighed. The tube with sample is placed inside the platinum wire coil and is inductively heated to a preset temperature. The pyroprobe system obtains heatup rates of $20^{\circ} \mathrm{C} / \mathrm{ms}$ to temperatures as high as $999^{\circ} \mathrm{C}$. The drawback of this system is that it heats to a single, preset temperature and holds that temperature for a maximum time of only $20 \mathrm{~s}$.

The combined MS/pyroprobe system was used to examine the decomposition compounds of interest by manually raising the temperature $50^{\circ} \mathrm{C}$ at 1 -min intervals. Initial experiments were performed with commercial sodium nitrate, sodium nitrite, and potassium ferrocyanide. These pure materials produced very little gas below $500^{\circ} \mathrm{C}$. A simulated SST salt cake containing sodium salts of nitrate, nitrite, phosphate, carbonate, and hydroxide started decomposing at a lower temperature, producing carbon dioxide at $300^{\circ} \mathrm{C}$, but no gaseous nitrogen products were produced until above $500^{\circ} \mathrm{C}$. Cesium nickel ferrocyanide was run neat and mixed with the simulated SST salt cake. The mixture of reductant (ferrocyanide) and oxidant (nitrate and nitrite) produced detectable gaseous products at $250^{\circ} \mathrm{C}$, at lower temperatures than either single component. These experiments were the first that gave an indication of gaseous products containing substantial quantities of nitrogen oxides ( $\mathrm{NO}$ and $\mathrm{N}_{2} \mathrm{O}$ ) and showed a mass 27 peak corresponding to hydrogen cyanide $(\mathrm{HCN})$.

Experiments were performed using the pyroprobe with the PNL-prepared, washed, In-Farm Flowsheet sodium nickel ferrocyanide (FECN-19) as precipitated without additional oxidant. Detectable gas products began with the $150^{\circ} \mathrm{C}$ pulse and were most abundant at $350^{\circ} \mathrm{C}$. The major gaseous products detected were ions of mass $18,28,30$, and 44 , with mass 18 water, mass 28 nitrogen and carbon monoxide, mass 30 nitric oxide, and mass 44 carbon dioxide and nitrous oxide. One limitation of the MS used is that both $\mathrm{N}_{2}$ and $\mathrm{CO}$ have mass 28 and both $\mathrm{N}_{2} \mathrm{O}$ and $\mathrm{CO}_{2}$ have mass 44 . Resolution of these gases by MS requires a high resolution instrument. The gases corresponding to mass 28 and 44 can be somewhat differentiated by examining ion mass 12 for atomic carbon, 14 for atomic nitrogen, and 16 for atomic oxygen. Substantial amounts of ion 27 corresponding to $\mathrm{HCN}$ were found. Mass ion 52 was also found, which is most likely cyanogen $\left(\mathrm{C}_{2} \mathrm{~N}_{2}\right)$. These data were the first to indicate the product gases as a function of temperature for the decomposition of synthetic, flowsheet ferrocyanide. The major problem in correlating these data with STG and DSC is that the temperature profile is much different. The materials are heated very rapidly and held at a temperature for only $20 \mathrm{~s}$ with the pyroprobe. Complete decomposition at a given temperature is not obtained as shown by continued gas evolution with multiple heating cycles at a set temperature. The STG and DSC experiments used a slow temperature-programmed heating rate of $5^{\circ} \mathrm{C} / \mathrm{min}$.

The pyroprobe more closely simulates the TTX experiments described in Section 4.4. By setting the pyroprobe to rapidly heat to $425^{\circ} \mathrm{C}$, above the known explosion initiation temperature, data indicating the gases produced from the small-scale explosions may be obtained. Results were obtained for the decomposition of In-Farm Flowsheet sodium nickel ferrocyanide (FECN-19). Decreased concentration of gases, approximately $20 \%$, were observed from a second heat pulse. The major ions detected were for mass 18 , 28,30 , and 44. As discussed earlier, ions of mass 12,14 , and 16 were examined in an attempt to deconvolute mass ions 28 and 44 . Because all the gases evolved at one time, no specific conclusions could be made. A relatively high abundance of mass 27 in the first heat pulses was found with none in the second. The material was removed after heatup, and the weight loss was $27.5 \%$. 
A temperature-programmed microfurnace was designed and constructed to better simulate the STG and DSC experiments. The sample holder was constructed out of ultrathin wall, $1 / 8$-in.-OD SS tubing. Heat was supplied by two 1/4-in. by 2 -in., 300-watt cylindrical heaters. An aluminum heat block 1 in. by 2 in. was drilled for the sample holder, two heaters, and a thermocouple. The temperature was programmed and controlled by a proportional band, solid-state controller. The temperature profile of the microfurnace was determined by locating a $1 / 8$-in. thermocouple in the sample position, running the controller through the program, and recording the temperature with a data logger. The controller was programmed for a temperature profile of a $5^{\circ} \mathrm{C} / \mathrm{min}$ heating rate starting at $50^{\circ} \mathrm{C}$ and going to $500^{\circ} \mathrm{C}$. The temperature at the sample location tracked the temperature program within $2^{\circ} \mathrm{C}$.

The temperature-programmed microfurnace was interfaced to the MS using the open-split interface. A 1 -m piece of 0.25 -mm-diameter fused silica column and a reducer fitting were used to connect the $1 / 8$-in.diameter sample holder to the MS. A flow controller was used to keep a constant helium flow of $10 \mathrm{~mL} / \mathrm{min}$ to sweep the gases out of the furnace into the MS. The sample was placed in a 0.095 -in. by 1-in. quartz tube similar to that used for the pyroprobe experiments and positioned in the center of the sample holder.

Experiments were performed using PNL-prepared flowsheet materials (FECN-19). The temperature range, $50^{\circ} \mathrm{C}$ to $500^{\circ} \mathrm{C}$, and heating rate, $5^{\circ} \mathrm{C} / \mathrm{min}$, simulated the conditions used for STG and DSC. The results from the temperature-programmed decomposition of FECN-19 are shown in Figure 4.7 for duplicate experiments with different sample sizes. To determine the temperature at any time, multiply the time by 5 and add 50. A rough scale has been added to the bottom of the trace. The duplicate experiments with sample sizes of $4.45 \mathrm{mg}$ and $7.66 \mathrm{mg}$ were found to be very reproducible. Only the total abundance of gases change as a function of sample size. The weight loss was also reproducible with $41.56 \%$ for the smaller sample and $41.38 \%$ for the larger.

The distribution of gases from FECN-19 is represented by the extracted ions $18,28,30$, and 44 , as shown in Figure 4.8. Deconvolution of mass 28 and 44 is accomplished by examining the extracted ions 12, 14, and 16, as shown in Figure 4.9. The figure shows that the first peak corresponding to $220^{\circ} \mathrm{C}$ contains very little carbon (mass 12 ), while the second peak, corresponding to $250^{\circ} \mathrm{C}$, shows increased amounts. At these same times the mass 44 ion has similar abundance. Interpretation of the data indicates that the first peak corresponds to the production of predominantly $\mathrm{N}_{2} \mathrm{O}$ and the second is $\mathrm{CO}_{2}$. The production of cyanide-containing gases at low temperature can be seen by examining the extracted ions 26,27 , and 52 shown in Figure 4.10. The decrease in mass 27 also corresponds to the increase in $\mathrm{CO}_{2}$. Apparently, pyrolytic decomposition occurs, producing reduced carbon species such as HCN until the temperature reaches a point where oxidation converts the carbon to carbon dioxide. Concentration of nitrogen (mass 28) is very small until the decomposition reaches temperatures of $350^{\circ} \mathrm{C}$ and above.

The gases produced during the thermal decomposition of PNL-prepared FECN-21, FECN-28b plus added sodium nitrate/nitrite, and WHC-prepared U-Plant Flowsheet ferrocyanide (WHC-1) were determined for comparative purposes. Figure 4.11 shows the relative differences in gas production from the various materials tested. FECN-21 was prepared by a flowsheet similar to FECN-19, yet the gas production appears quite different. The U-Plant Flowsheet ferrocyanide produced very little gas, most likely because it contained so little ferrocyanide. The addition of extra sodium nitrate/nitrite also changes 


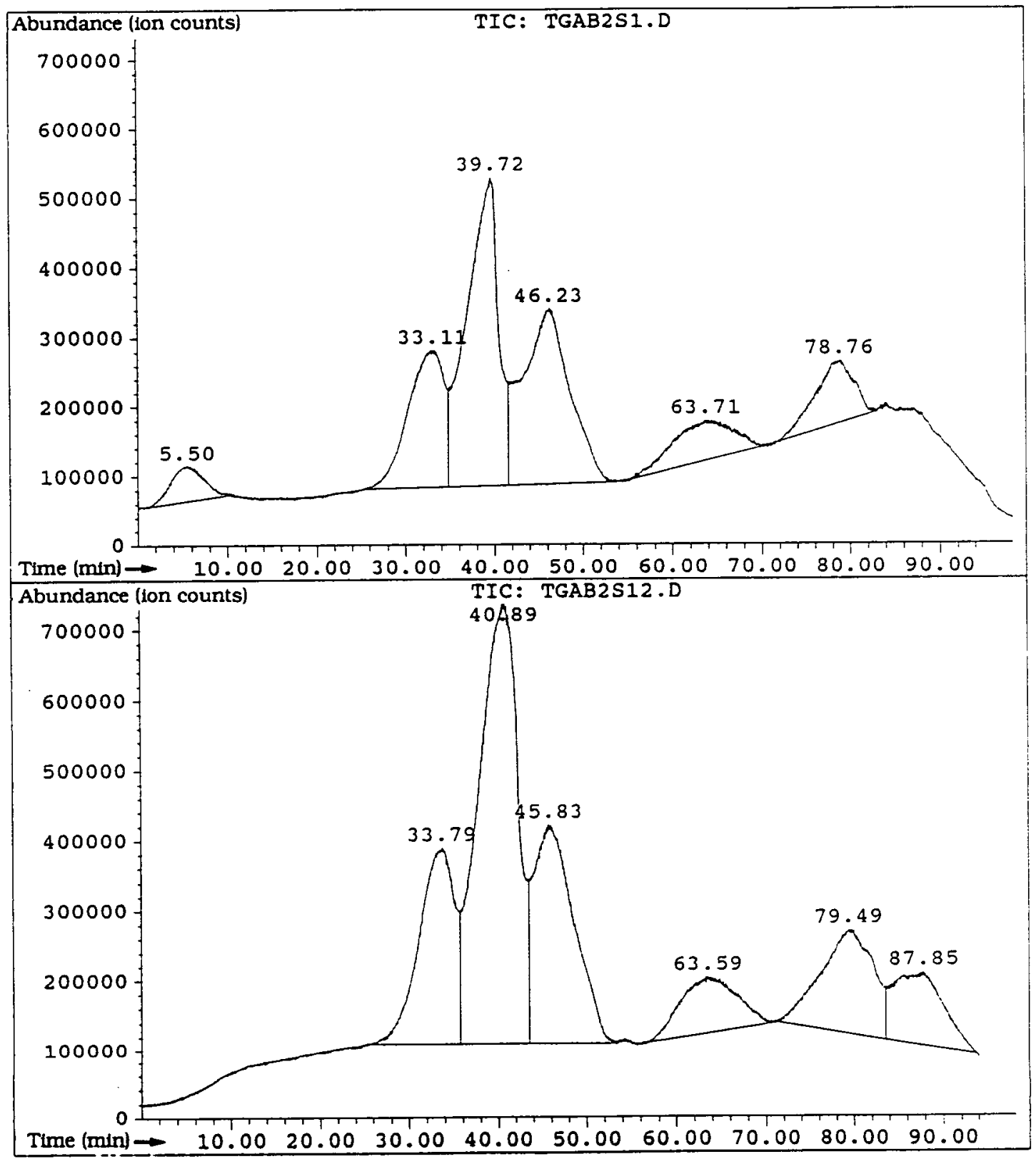

Figure 4.7. Duplicate Experiments of Different Sample Sizes Showing Total Ion Traces for the Thermal Decomposition of Washed In-Farm Flowsheet Ferrocyanide Solids (FECN-19)

the gas product as shown by the results from FECN-28b. One of the major differences is the production of nitrogen at lower temperature for FECN-21 and FECN-28b, as shown in Figure 4.12. Production of nitrogen corresponds to the most energetic reaction for ferrocyanide/nitrate reactions. 


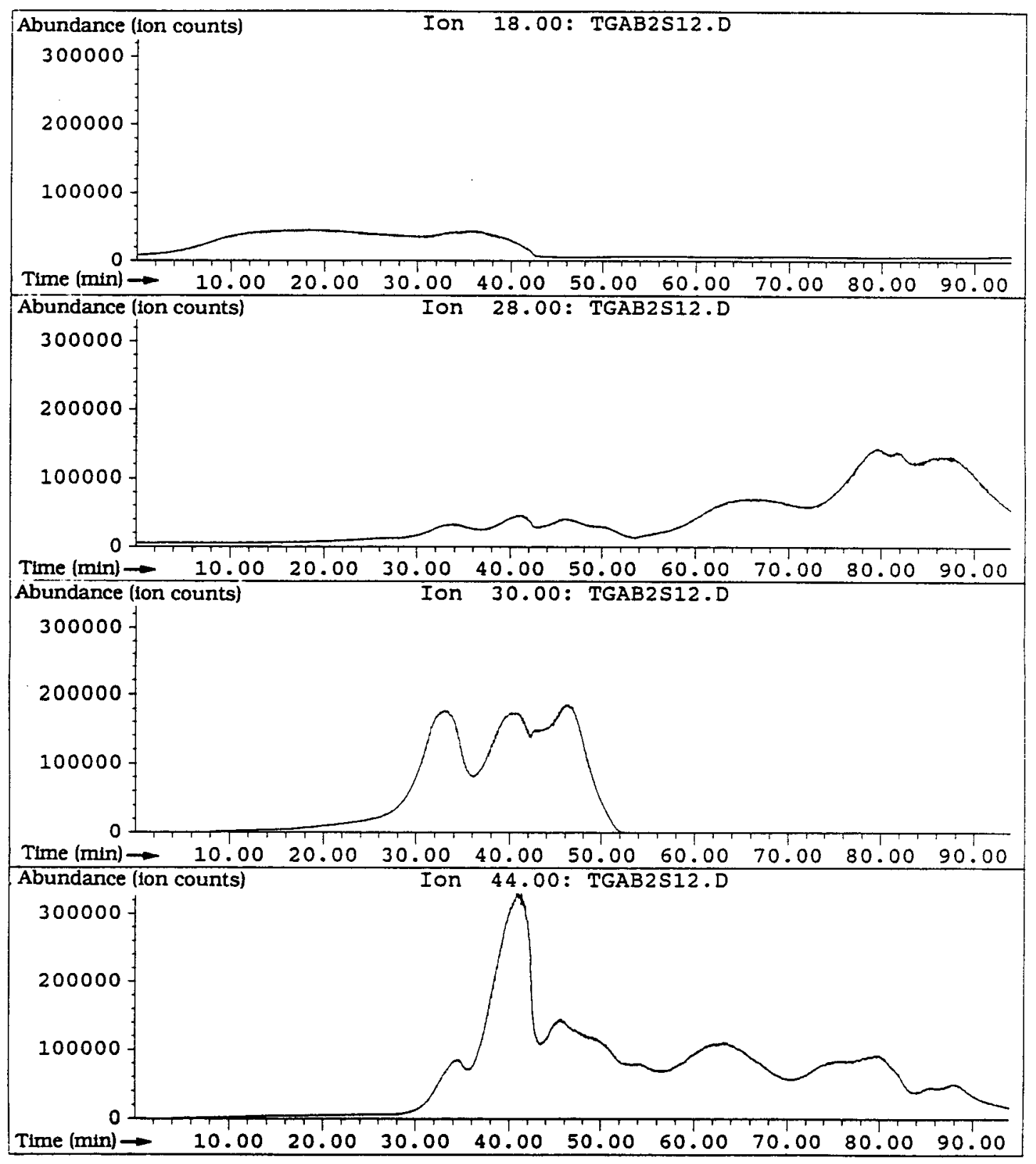

Figure 4.8. Extracted Ion Traces for the Major Mass Ions $(18,28,30$, and 44) for the Thermal Decomposition of Washed In-Farm Flowsheet Solids (FECN-19)

\subsubsection{Conclusions}

A temperature-programmed microfurnace was fabricated and interfaced to a mass spectrometer for monitoring of gaseous products from the thermal decomposition of simulated ferrocyanide-containing wastes. The first substantial production of gaseous products occurred at temperatures around $220^{\circ} \mathrm{C}$. The 


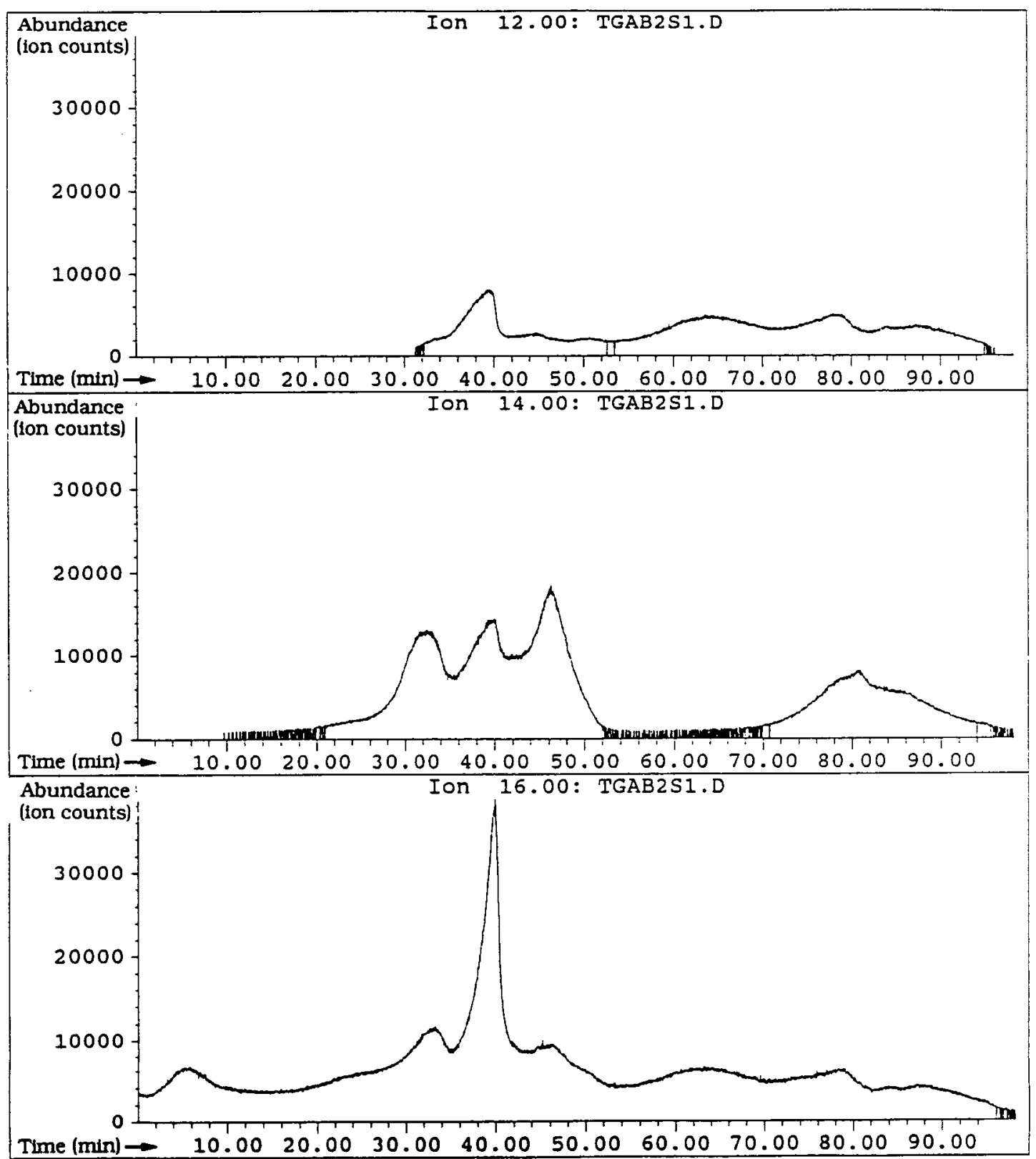

Figure 4.9. Extracted Ion Traces for Carbon (Mass 12), Nitrogen (Mass 14), and Oxygen (Mass 16) from the Thermal Decomposition of Washed In-Farm Ferrocyanide Solids (FECN-19)

major components were nitrogen oxides and carbon dioxide. Both hydrogen cyanide and cyanogen were also detected in small amounts. Production of substantial quantities of nitrogen occurred above $300^{\circ} \mathrm{C}$. The U-Plant Flowsheet material produced only trace quantities of gases resembling the behavior of sodium nitrate/nitrite mixtures. 


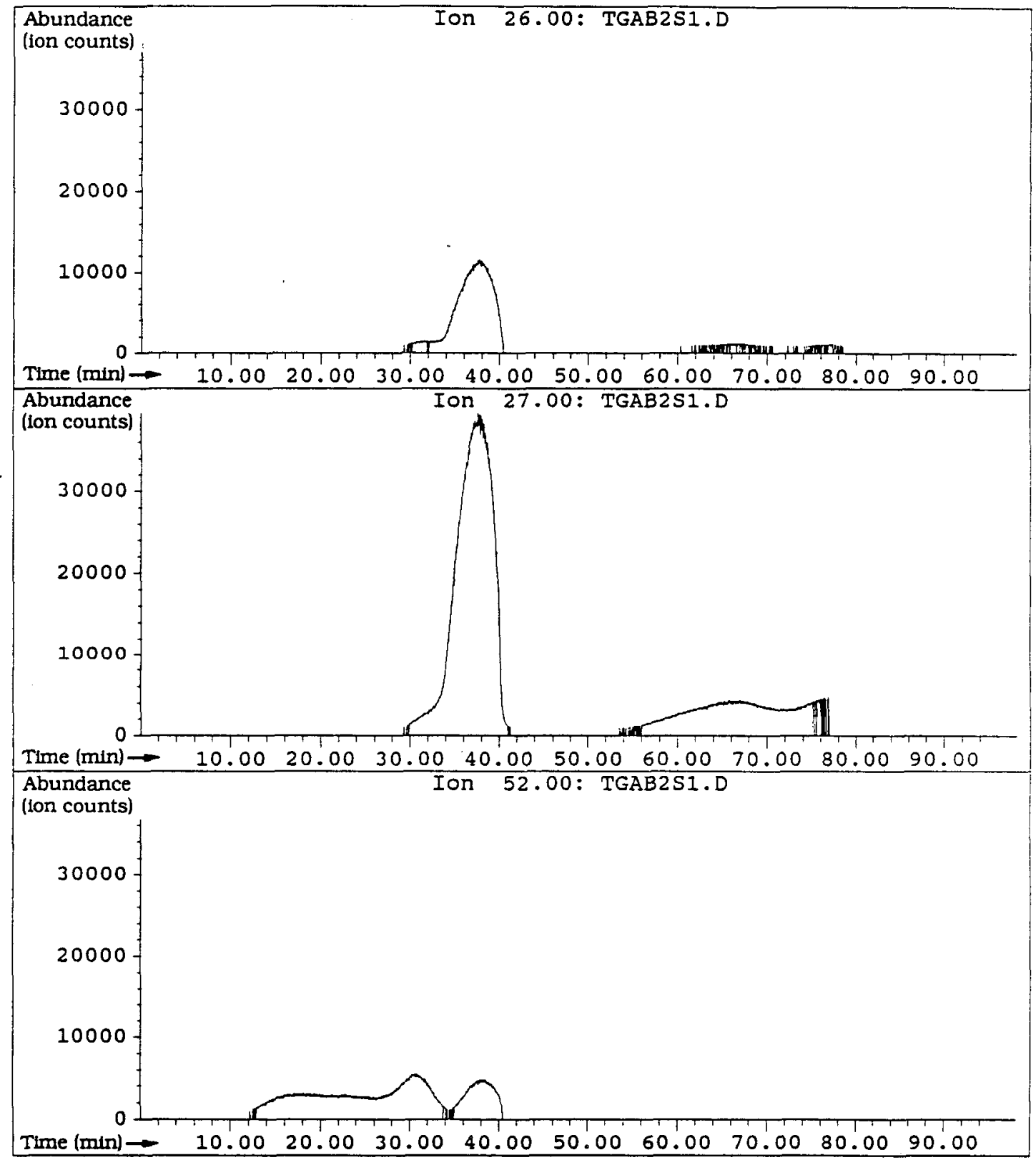

Figure 4.10. Extracted Ion Traces for Mass Ions 26, 27, and 52 from the Thermal Decomposition of Washed In-Farm Ferrocyanide Solids (FECN-19)

\subsubsection{Future Work}

The major activity to be completed is to determine the temperature of reactions and gases produced during the thermal decomposition of flowsheet ferrocyanides in the presence of oxygen. The major limitation of the MS is the inability to use air or oxygen as a sweep gas during the ferrocyanide decomposition. The gases produced and temperature at which the reaction initiates can be influenced by the presence of 


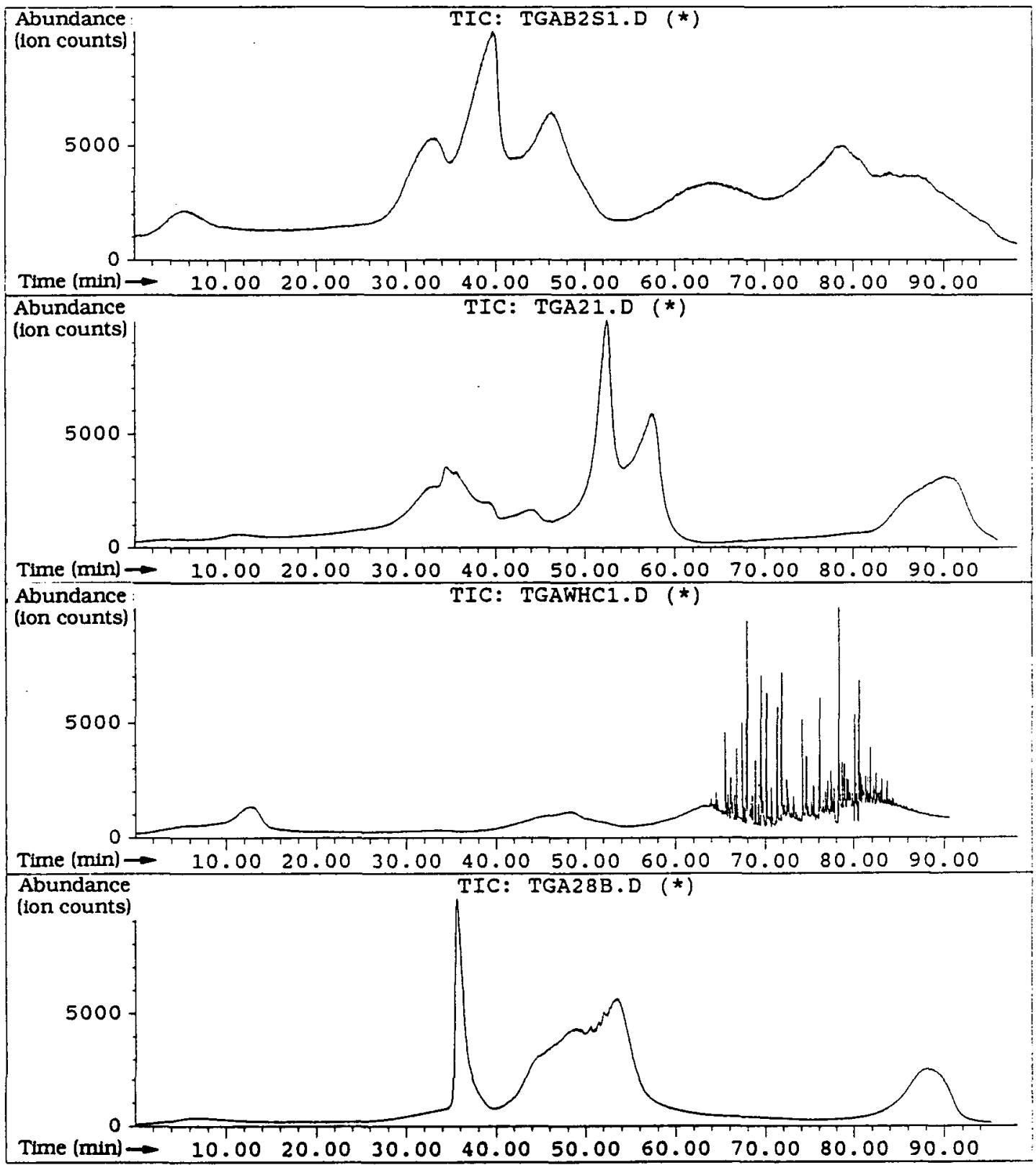

Figure 4.11. Total Ion Traces for the Thermal Decomposition of Flowsheet Materials: FECN-19, FECN-21, WHC-1, and FECN-28b Plus Nitrate/Nitrite

oxygen. A major question to be answered is if the cyanide-containing gases are produced with oxygen present. This would be easy to determine by fourier transform infrared spectroscopy (FTIR) by monitoring the strong $\mathrm{CN}$ absorbance. The microfurnace used for the MS experiments can easily be interfaced to a small-volume gas flow cell on a conventional FTIR; this activity is pending procurement of the FTIR. Data from the DXRD experiments will be examined to determined if further studies are warranted. 


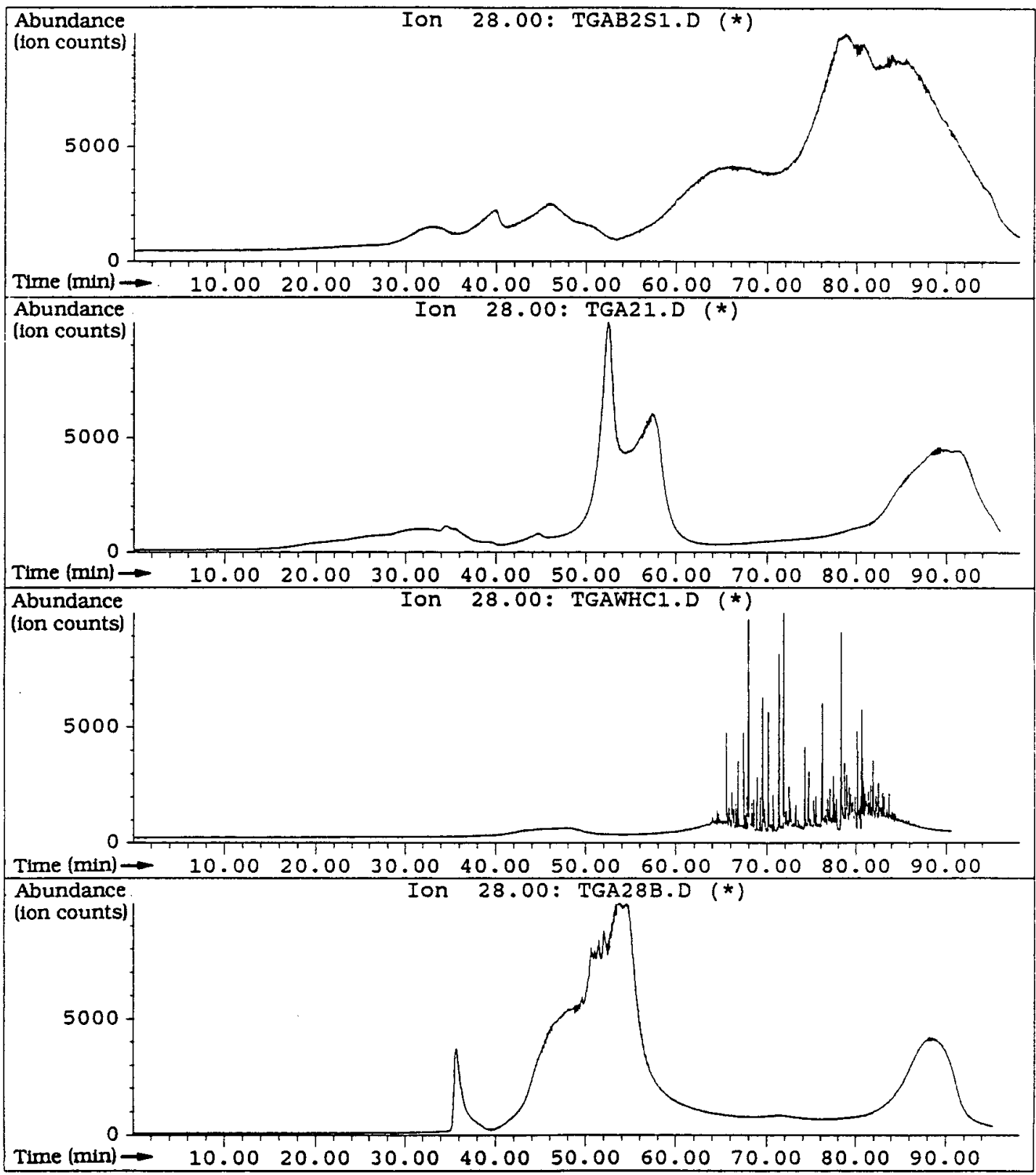

Figure 4.12. Extracted Ion Traces for Mass Ion 28 for the Thermal Decomposition of Flowsheet Materials: FECN-19, FECN-21, WHC-1, and FECN-28b

\subsection{Energetic Studies of Ferrocyanide-Containing Wastes}

The purpose of this task is to investigate the chemical reactivity and relative explosivity of various ferrocyanide-containing synthetic wastes. 


\subsubsection{Work Accomplished}

During FY 1991, enthalpy changes were calculated for a variety of reactions between possible ferrocyanide precipitates and nitrates/nitrites using estimates for the ferrocyanide enthalpy of formation. The enthalpy values for sodium nickel ferrocyanide were used to calculate the amount of diluent required to dissipate the heat generated by nitrate/nitrate oxidation at a variety of temperatures. TTX tests were used to determine the explosivity of ferrocyanide precipitate and oxidant mixtures prepared by the Preparation and Characterization Task and to investigate the effects of selected potential catalysts and initiators. Thermal analysis techniques, DSC and STG, were used to determine the thermal behavior of the simulated ferrocyanide wastes.

Thermodynamic calculations were performed to determine the theoretical energy of various oxidation reactions of cyanide-containing compounds including ferrocyanide. The energetics of the oxidation of the compounds tested can be estimated from enthalpies of formation for the reactants and products. They are highly dependent upon the reaction products. Products from the reaction of ferrocyanides with either nitrate or nitrite salts may include $\mathrm{N}_{2}, \mathrm{CO}_{2}, \mathrm{CO}, \mathrm{NO}, \mathrm{N}_{2} \mathrm{O}, \mathrm{Na} 2 \mathrm{O}, \mathrm{NaOH}, \mathrm{Na}_{2} \mathrm{CO}_{3}, \mathrm{NiO}, \mathrm{FeO}, \mathrm{Fe}_{2} \mathrm{O}_{3}$, and traces of $\mathrm{C}, \mathrm{C}_{2} \mathrm{~N}_{2}$, and other compounds. The calculated energy release is highly sensitive to the products formed, and the reactions can be endothermic for products such as NO, as shown in Table 4.7. If a sizable fraction of the carbon goes to $\mathrm{CO}$ or other reduced carbon species, the energy is greatly reduced. In contrast, the variation from one cyanide compound to another makes very little difference.

If an explosion were to occur, aerosols would be formed. Theory predicts that the predominant sodium product is the carbonate up to about $1800^{\circ} \mathrm{C}$ at which point decomposition to the oxide becomes appreciable. Above about $1900^{\circ} \mathrm{C}$ the decomposition of the oxide itself becomes important. However, if water vapor is present, sodium hydroxide becomes the most stable sodium form above about $1700^{\circ} \mathrm{C}$. At this temperature sodium hydroxide would be a vapor. Without knowing the final temperature and the components in the reactive mixture a single reaction cannot be predicted based on thermodynamics. Secondly, there is no reason to expect that equilibrium is reached among the products formed during an explosive reaction.

Table 4.7. Calculated Enthalpy Changes for Oxidation of Some Cyanides and Ferrocyanides

\begin{tabular}{|c|c|c|c|}
\hline Compound & Oxidant & Products $^{(a)}$ & $\underline{\Delta \mathrm{H}, \mathrm{kJ} / \mathrm{mol}}$ \\
\hline $\mathrm{Na}_{2} \mathrm{NiFe}(\mathrm{CN})_{6}$ & $\mathrm{NaNO}_{3}$ & $\mathrm{Na}_{2} \mathrm{CO}_{3}, \mathrm{CO}_{2}, \mathrm{~N}_{2}$ & -3012 \\
\hline$n$ & $n$ & $\mathrm{Na}_{2} \mathrm{O}, \mathrm{CO}_{2}, \mathrm{~N}_{2}$ & -1722 \\
\hline$n$ & $n$ & $\mathrm{Na}_{2} \mathrm{O}, \mathrm{CO}, \mathrm{N}_{2}$ & -240 \\
\hline$n$ & $n$ & $\mathrm{Na}_{2} \mathrm{CO}_{3}, \mathrm{Na}_{2} \mathrm{O}, \mathrm{NO}$ & +230 \\
\hline$n$ & $\mathrm{NaNO}_{2}$ & $\mathrm{Na}_{2} \mathrm{CO}_{3}, \mathrm{~N}_{2}$ & -3708 \\
\hline $\mathrm{Ni}_{2} \mathrm{Fe}(\mathrm{CN})_{6}$ & $\mathrm{NaNO}_{3}$ & $\mathrm{Na}_{2} \mathrm{CO}_{3}, \mathrm{CO}_{2}, \mathrm{~N}_{2}$ & -2880 \\
\hline$n$ & $\mathrm{NaNO}_{2}$ & $\mathrm{Na}_{2} \mathrm{CO}_{3}, \mathrm{CO}_{2}, \mathrm{~N}_{2}$ & -3480 \\
\hline $\mathrm{NaCN}$ & $\mathrm{NaNO}_{3}$ & $\mathrm{Na}_{2} \mathrm{CO}_{3}, \mathrm{~N}_{2}$ & -3450 \\
\hline
\end{tabular}

(a) Other products are $\mathrm{FeO}, \mathrm{Fe}_{2} \mathrm{O}_{3}$ and $\mathrm{NiO}$. 
For a ferrocyanide/oxidant reaction, it is estimated that the maximum energy released is about $3300 \mathrm{~kJ} / \mathrm{mol}$ of ferrocyanide or $3.7 \mathrm{~kJ} / \mathrm{g}$ of ferrocyanide. This is for a theoretical stoichiometric mixture of sodium nickel ferrocyanide $(1.0 \mathrm{~g})$ and a $50 / 50 \mathrm{~mol} \% \mathrm{mix}$ of sodium nitrate/sodium nitrite $(1.6 \mathrm{~g})$ yielding $\mathrm{N}_{2}$ and $\mathrm{CO}_{2}$.

Diluents in the reaction mix are expected to be extremely important. They may change the thermal conductivity thus influencing the propagation of the reaction; change the rates of bi-molecular steps; and most importantly, they introduce a heat capacity which will control the temperature rise in an adiabatic process. Diluents likely to be present in the ferrocyanide tanks include water; excess sodium nitrate and nitrite; aluminates; a variable mix of other possible components such as silicates, sulfates, phosphates, hydroxides, and carbonates; and metal salts of iron and bismuth.

As a way to estimate the effects of selected waste constituents as diluents, heat capacity data and an assumption that the oxidation reaction is $80 \%$ efficient were used to calculate the quantity of water; excess sodium nitrate; and a model diluent, sodium aluminate, that would prevent the mixture from reaching specific temperatures. These data are presented in Table 4.8. Water is the best diluent due to the large vaporization enthalpy. While free water is easily lost, that combined as hydrates or in the physical structure may remain until $150^{\circ} \mathrm{C}$ to $250^{\circ} \mathrm{C}$ temperatures are reached. The enthalpy of fusion of sodium nitrate aids in preventing a temperature rise in the vicinity of $300^{\circ} \mathrm{C}$. A thermal runaway reaction is precluded if sufficient diluent is present. In these simplified models all solid-state transitions, including the decomposition of hydrates, were ignored. The hydrate decomposition was approximated in the calculated water vaporization.

Time-to-explosion experiments were performed to determine the relative explosivity of a variety of synthetic ferrocyanide wastes. TTX data were generated using the modified Henkin test with 40 to $100 \mathrm{mg}$ samples contained in a 5-mm-diameter thin wall (NMR) tube. Experimental difficulties were encountered with the sodium nickel ferrocyanides. The sodium nickel ferrocyanides typically were higher hydrates than the cesium nickel ferrocyanide previously tested. The high water content tended to cause foaming in the NMR tube thus carrying the contents out of the heated zone and quenching the reaction. This problem was solved by drying the ferrocyanide at $160^{\circ} \mathrm{C}$ overnight.

Table 4.8. Estimated Quantity of Diluent Required to Prevent Propagation of Ferrocyanide Oxidation

\begin{tabular}{|c|c|c|c|}
\hline \multirow[b]{2}{*}{ Reaction Temp. ${ }^{\circ} \mathrm{C}$} & \multicolumn{2}{|c|}{ g Diluent/g Ferrocyanide (a) } & \multirow[b]{2}{*}{200} \\
\hline & $307^{(b)}$ & 250 & \\
\hline $\mathrm{H}_{2} \mathrm{O}, \mathrm{g}$ & $2.7(2.4)^{(c)}$ & $2.9(2.6)$ & $3.0(2.7)$ \\
\hline $\mathrm{NaNO}_{3}, \mathrm{~g}$ & $11.4(10.5)$ & $16.8(14.9)$ & $23.7(21.3)$ \\
\hline $\mathrm{NaAlO}_{2}, \mathrm{~g}$ & $23.3(20.0)$ & $31.4(27.3)$ & $44.8(39.7)$ \\
\hline
\end{tabular}

(a) Reaction mix is $1.0 \mathrm{~g} \mathrm{Na}_{2} \mathrm{NiFe}(\mathrm{CN})_{6}+1.61 \mathrm{~g} \mathrm{NaNO}_{3}$ assuming $80 \%$ of theoretical.

(b) Calculations at $307^{\circ} \mathrm{C}$ assume that runaway reaction requires melting of $\mathrm{NaNO}_{3}$. Calculations at other temperatures assume reaction can occur without fusion of the $\mathrm{NaNO}_{3}$.

(c) Values in ( ) assume each molecule of ferrocyanide retains 4 waters of hydration. 
Table 4.9 lists typical data obtained for the TTX testing. The estimated minimum explosion temperature is extrapolated from data similar to those presented in Figure 4.13. These results support earlier observations that the cesium nickel ferrocyanide is more stable than compounds with a higher nickel content or the sodium nickel analogs.

Figure 4.13 compares the times for explosion for two sodium nickel ferrocyanides prepared using the In-Farm Flowsheet (FECN-19,-21) and one prepared using the U-Plant Flowsheet (WHC-1). The In-Farm settled and unwashed material is FECN-21, and the centrifuged and washed plus equimolar sodium nitrate/nitrite is FECN-19 plus a theoretical amount of equimolar sodium nitrate and nitrite. The homogenized U-Plant sample is WHC-1 after drying. The settled In-Farm solids behaved similarly to a relatively pure sodium nickel ferrocyanide mixed with sodium nitrate and nitrite. The U-Plant material did not explode after $20 \mathrm{~min}$ at $400^{\circ} \mathrm{C}$.

The data illustrate that there is sufficient oxidant in the precipitated ferrocyanide from the residual interstitial solution for the settled In-Farm waste to explode when dry. The ferrocyanide concentration $(\mathbf{1 . 7 \%})$ in the U-Plant material is sufficiently dilute that it does not explode in this test.

Table 4.9. Time-to-Explosion Data for Small Samples

\begin{tabular}{|c|c|c|c|}
\hline Compound & Added Oxidant $^{(a)}$ & $\begin{array}{l}\text { Explosion Time } \\
\text { at } 360^{\circ} \mathrm{C}, \mathrm{s} \\
\end{array}$ & $\begin{array}{c}\text { Estimated Minimum } \\
\text { Explosion } \mathrm{T},{ }^{\circ} \mathrm{C} \\
\end{array}$ \\
\hline $\mathrm{Cs}_{2} \mathrm{NiFe}(\mathrm{CN})_{6}(\mathrm{FECN}-14)$ & $\mathrm{Na}\left(\mathrm{NO}_{3}, \mathrm{NO}_{2}\right)$ & 50 & 340 \\
\hline $\mathrm{Cs}_{2} \mathrm{NiFe}(\mathrm{CN})_{6}(\mathrm{FECN}-14)$ & $(\mathrm{Na}, \mathrm{K}) \mathrm{NO}_{2}$ & 33 & 300 \\
\hline $\mathrm{Cs}_{2} \mathrm{NiFe}(\mathrm{CN})_{6}(\mathrm{FECN}-14)$ & $(\mathrm{Na}, \mathrm{K}) \mathrm{NO}_{2}$ & 15 & 310 \\
\hline $\mathrm{KCN}$ & $\mathrm{Na}\left(\mathrm{NO}_{3}, \mathrm{NO}_{2}\right)$ & 240 & 350 \\
\hline $\mathrm{Na}_{2} \mathrm{NiFe}(\mathrm{CN})_{6}{ }^{(\mathrm{b})}(\mathrm{FECN}-28)$ & $\mathrm{Na}\left(\mathrm{NO}_{3}, \mathrm{NO}_{2}\right)$ & 27 & 295 \\
\hline $\mathrm{NaNiFe}(\mathrm{CN})_{6}{ }^{(\mathrm{c})}(\mathrm{FECN}-23)$ & $\mathrm{Na}\left(\mathrm{NO}_{3}, \mathrm{NO}_{2}\right)$ & 13 & 290 \\
\hline In-Farm Waste ${ }^{(d)}($ FECN-21) & None $^{(d)}$ & 40 & 310 \\
\hline WHC-2 & $\mathrm{Na}\left(\mathrm{NO}_{3}, \mathrm{NO}_{2}\right)$ & 35 & 300 \\
\hline
\end{tabular}

(a) Slight stoichiometric excess of axidant.

(b) The $\mathrm{Na} / \mathrm{Ni}$ ratio is uncertain.

(c) Although high in $\mathrm{Ni}$ the compound still contains some alkali metal ions.

(d) Ferricyanide compound.

(e) Settled, unwashed, and dried, synthetic In-Farm Flowsheet waste. Waste contains $\mathrm{Na}\left(\mathrm{NO}_{3}, \mathrm{NO}_{2}\right)$. 


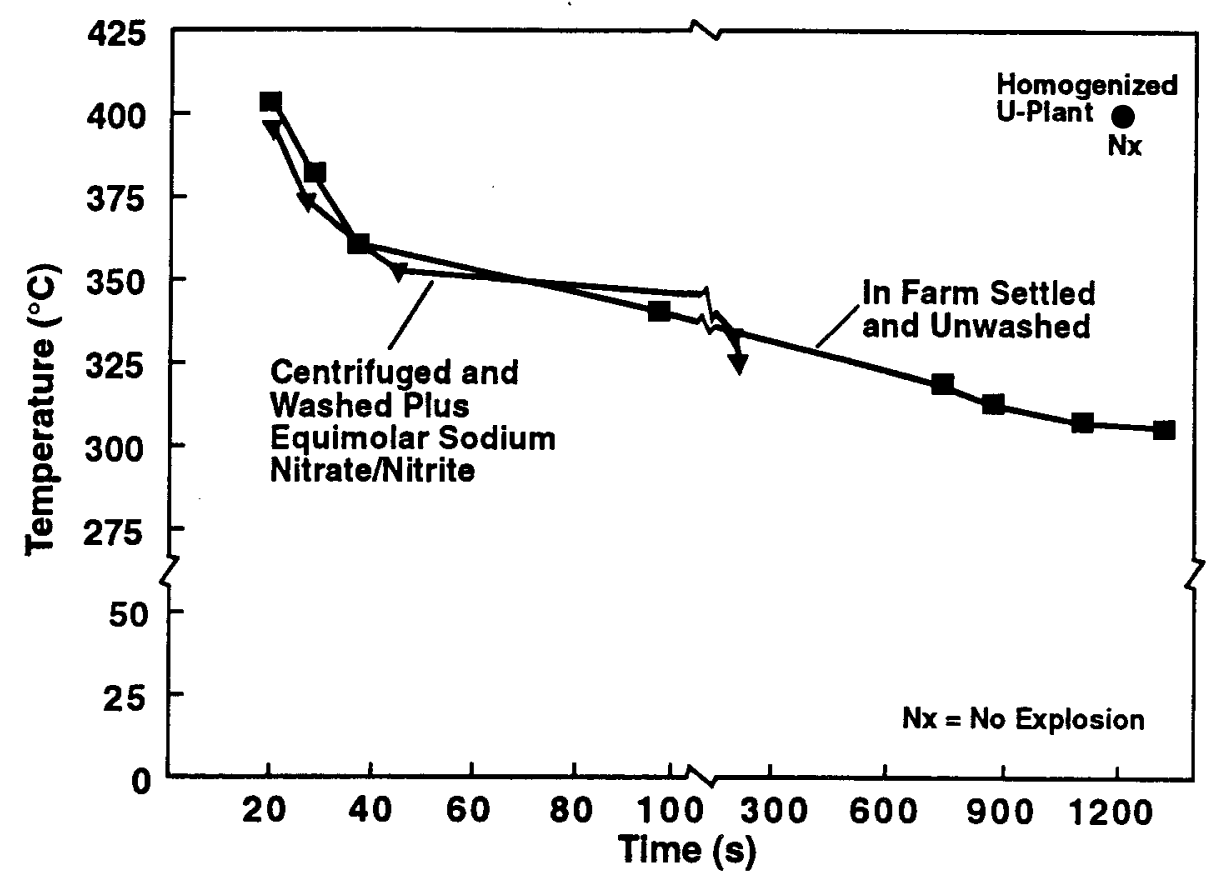

Figure 4.13. Time-to-Explosion Data for FECN-21, WHC-1, and FECN-19 Mixed with Equimolar Sodium Nitrate/Nitrite

A preliminary set of TTX experiments was also performed to determine the effect of selected potential catalysts and/or initiators on the reaction between equimolar sodium nitrate and nitrite on 1) sodium nickel ferrocyanide and 2) sodium nickel ferricyanide. The study was designed to allow analysis of the results using statistical methods to identify those factors having a significant effect.

In this study, ferric hydroxide, chromic hydroxide, nickel hydroxide, or EDTA were added individually at 0.03 mole per mole ferrocyanide. This concentration was selected because it was assumed to be sufficient to provide an effect if one existed. The oxidant to $\mathrm{Na}_{2} \mathrm{NiFe}(\mathrm{CN})_{6}$ ratio was slightly greater than the stoichiometric amount needed.

Preliminary analysis of the results suggests that none of these materials acts as a catalyst or initiator for the nitrate and nitrite oxidation of $\mathrm{Na}_{2} \mathrm{NiFe}(\mathrm{CN})_{6}$. This is in contrast to the results from mixtures of these materials with cesium nickel ferrocyanide and equimolar sodium nitrate and nitrite reported earlier (Burger and Scheele 1991).

Thermal analyses using both DSC and STG have been made on the ferrocyanide compounds in air alone, and with mixtures of nitrates and nitrites in air and in nitrogen. Analyses of the settled and dried $\mathrm{Na}_{2} \mathrm{NiFe}(\mathrm{CN})_{6}$ prepared using the In-Farm Flowsheet are shown for the DSC in Figure 4.14 and for the STG in Figure 4.15. These two analyses indicate that an exothermic reaction begins at about $230^{\circ} \mathrm{C}$ for this material. Other analyses with added nitrate and nitrite show similar behavior. These analyses indicate, as did the TTX test results for the same material, that nitrate and nitrite from the nominal $6 \underline{\mathrm{M}}$ nitrate plus nitrite solution are present in significant quantities in settled ferrocyanide precipitates. 


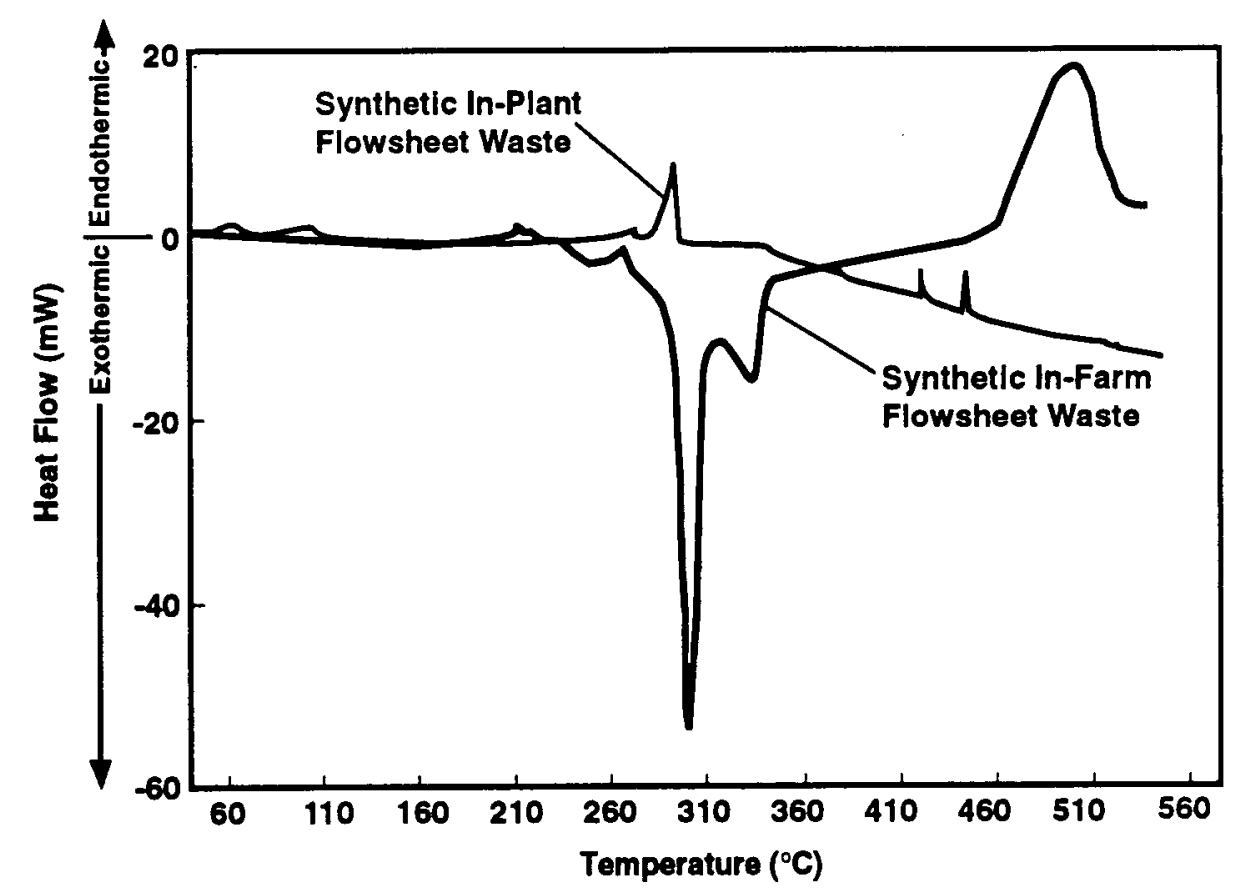

Figure 4.14. Differential Scanning Calorimetry of Settled and Dried Sodium Nickel Ferrocyanide Prepared Using In-Farm and U-Plant Flowsheets

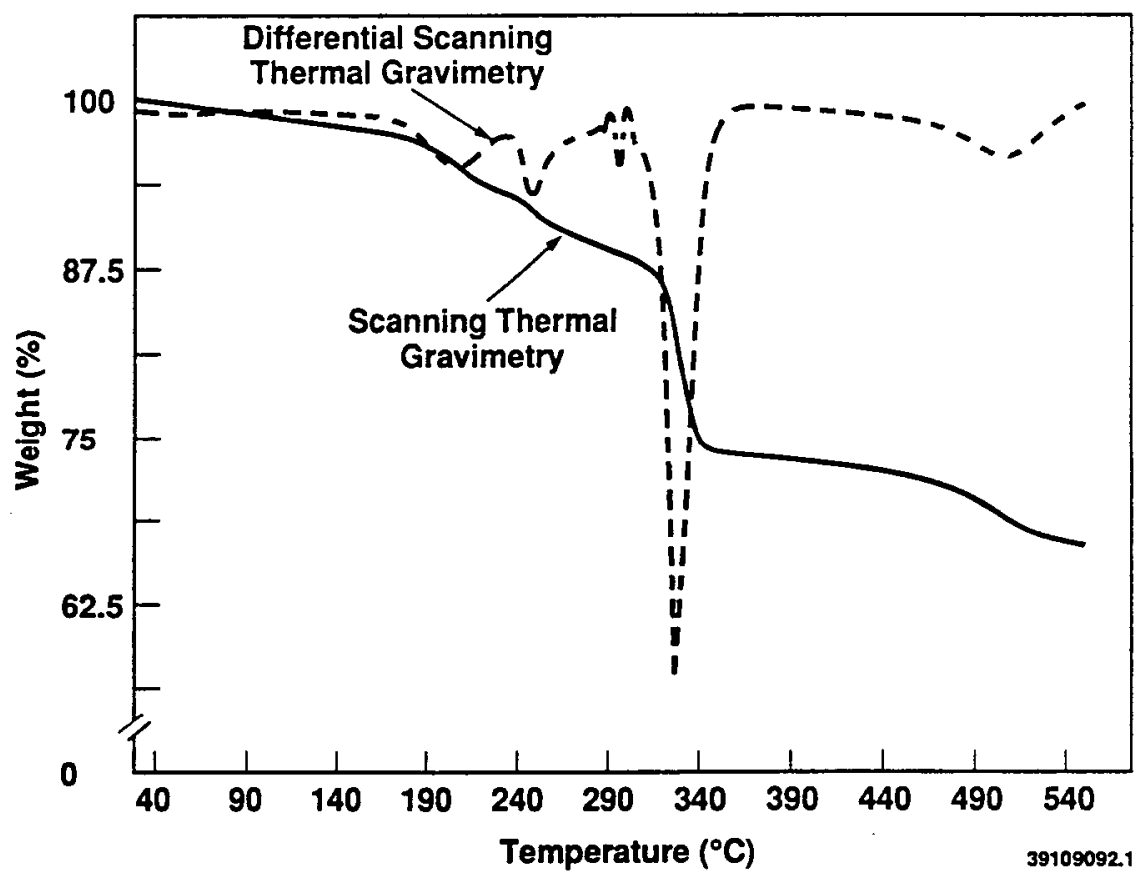

Figure 4.15. Scanning Thermogravimetry of Settled and Dried Sodium Nickel Ferrocyanide Prepared Using In-Farm Flowsheet 
Figure 4.14 also shows the lack of exothermic behavior for the U-Plant Flowsheet sample WHC-1. Given the $1.7 \mathrm{wt} \%$ ferrocyanide in WHC-1, minimal detectable exothermic behavior is expected. Any exothermic behavior appears to occur during an endothermic event, possibly near $270^{\circ} \mathrm{C}$.

Salient features of the DSC plots are the temperature at the beginning of the exothermic reaction, the temperature at the exotherm maximum, and the general complexity (multiple peaks) of the exotherms. The STG provides similar information only with respect to weight loss instead of enthalpy. The complexity of the curves suggest that a complex (stepwise) reaction occurs with mixed sodium nitrate and nitrite oxidant.

\subsubsection{Conclusions}

Thermodynamic calculations for several postulated potential reactions of ferrocyanide with sodium nitrate or sodium nitrite indicate that the reaction mechanism can dramatically affect the heat of reaction. The enthalpies of reaction range from an exothermic $3700 \mathrm{~kJ} / \mathrm{mol}$ ferrocyanide to an endothermic $200 \mathrm{~kJ} / \mathrm{mol}$ ferrocyanide. This suggests that by controlling the conditions of the reaction, the reaction products could be controlled as well as the heat produced.

Thermodynamic calculations to predict the effect of additional waste constituents on the reaction between $1 \mathrm{~g}$ of sodium nickel ferrocyanide and a stoichiometric amount of sodium nitrate indicate that small amounts of water and larger amounts of other potential waste constituents can prevent the reaction mixture from achieving high temperatures. It would require $3 \mathrm{~g}$ of water, $23.7 \mathrm{~g}$ of excess sodium nitrate, or $45 \mathrm{~g}$ of sodium aluminate to prevent temperatures from exceeding $200^{\circ} \mathrm{C}$ due to the heat of reaction. Lesser amounts of each of these diluents would allow temperatures to reach higher levels, thus allowing higher reaction rates.

The thermal explosivity testing results indicate that dried, settled In-Farm Flowsheet solids have sufficient nitrate and nitrite to exhibit a similar explosivity in the PNL TTX test to washed sodium nickel ferrocyanide mixed with a stoichiometric amount of equimolar sodium nitrate and nitrite. In the TTX tests the minimum observed explosion temperature for these two mixtures was nominally $310^{\circ} \mathrm{C}$. In contrast, the U-Plant synthetic waste provided by WHC did not explode at $400^{\circ} \mathrm{C}$ after heating for $20 \mathrm{~min}$. The lowest explosion temperature of $295^{\circ} \mathrm{C}$ was for a well-dried stoichiometric mix of FECN-28 and equimolar sodium nitrate and nitrite.

The DSC and STG studies indicate that the minimum exothermic reaction temperature for sodium nickel ferrocyanide and equimolar sodium nitrate and nitrite and dried, settled In-Farm Flowsheet solids is about $230^{\circ} \mathrm{C}$. The DSC and STG results indicate the oxidation reactions between sodium nickel ferrocyanide and the nitrate/nitrite mixture are complex, proceeding in multiple steps.

\subsubsection{Future Work}

The catalyst and initiator studies will be continued in FY 1992. Actual experiments will be performed to determine the effect of added diluents. The reactivity and explosivity of synthetic ferrocyanide wastes from other scavenging flowsheets will be tested. Reaction sensitivity studies are planned at LANL for several different ferrocyanide-containing synthetic waste mixtures. 


\subsection{Ferrocyanide Detection and In-Situ Waste Characterization: Development of an Electromagnetic Induction Method for Measuring Water Concentration in SST Waste}

This task focuses on measuring the water concentration in simulated SST waste material using an electromagnetic induction technique. Measurements of this type are performed by inserting a small probe in or near the simulant. The probe senses changes in electrical resistivity that can be correlated with moisture content. Once the moisture measurement system is calibrated for percent water concentration, under known SST conditions, moisture content can be continuously monitored.

\subsubsection{Work Accomplished}

The moisture measurement has been used successfully by lowering the induction coil sensor down a nonmetallic pipe (similar to a liquid observation well) or simply attaching the sensor coil to a probe and forcing it into a soft substance. Further testing will be required to determine the largest distance from the sensor at which this technique can provide accurate moisture information for a given situation.

The laboratory test equipment needed to evaluate this method of moisture detection in SSTs was procured and assembled into a functional electrical impedance measurement system. A test vessel for containing the simulated waste material during percent-moisture calibration was designed and fabricated. The induction coils for measuring the electrical conductivity of the simulant were also designed, fabricated, and characterized for this application. Temperature sensors accurate to $0.1^{\circ} \mathrm{C}$ were connected to the moisture sensors to account for temperature-dependent conductivity changes, since electrical conductivity is related to both temperature and moisture content of the waste material.

After the complete system was assembled, some preliminary tests were performed. Figure 4.16 shows the test vessel, sensor probe, HP4194 impedance analyzer, digital voltmeter for temperature control, and computer for data acquisition. Figure 4.17 shows the impedance characteristics of the induction coils in air, without simulant. The impedance curves displayed in Figure 4.17 provide information for selecting the best frequency range to operate the induction coils. To match the input impedance of the HP4194 impedance analyzer with the induction coils, a 2 to $8 \mathrm{kHz}$ frequency range appears to be the best choice.

The simulant synthesized for this task was a Bismuth Phosphate waste; however, only very preliminary measurements were made on this substance. Several series of measurements are required to calibrate the system for moisture content in a given simulant. After building and testing the system insufficient time remained for calibration.

\subsubsection{Conclusions}

Similar systems have been used successfully to measure water concentration in mud (consisting of many different soil types) and rock formations, but no definite conclusions were reached on how well this same concept could be used in simulated SST wastes. After designing, procuring, and assembling the moisture measurement system and manufacturing simulants, insufficient funds remained to perform calibration tests for determining the water content of simulated SST waste material. Repeatable calibration tests are essential to assessing the feasibility of this moisture measurement method. 


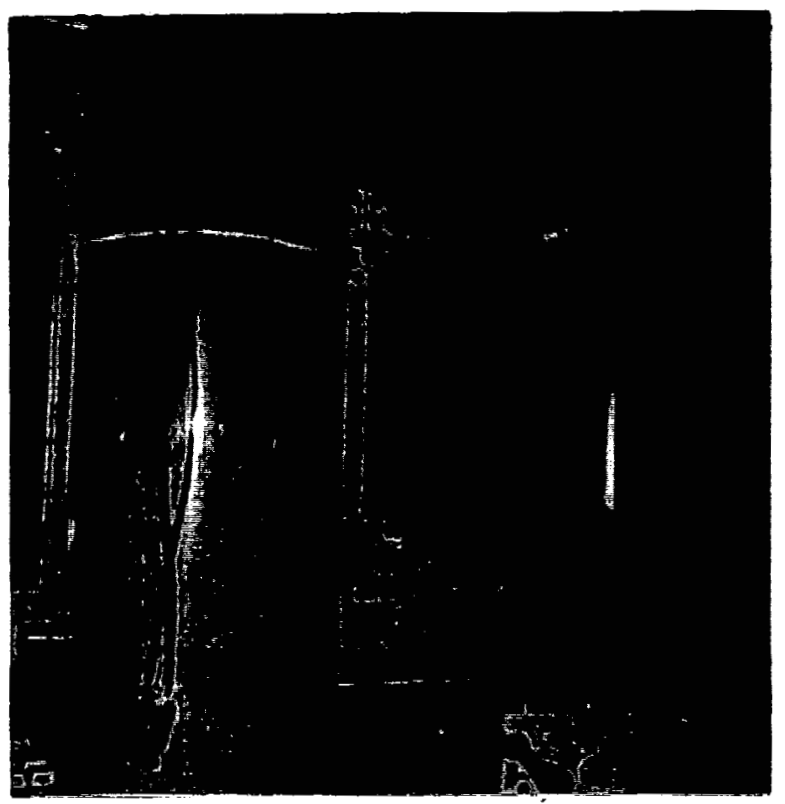

Figure 4.16. Equipment for Moisture Measurement Studies

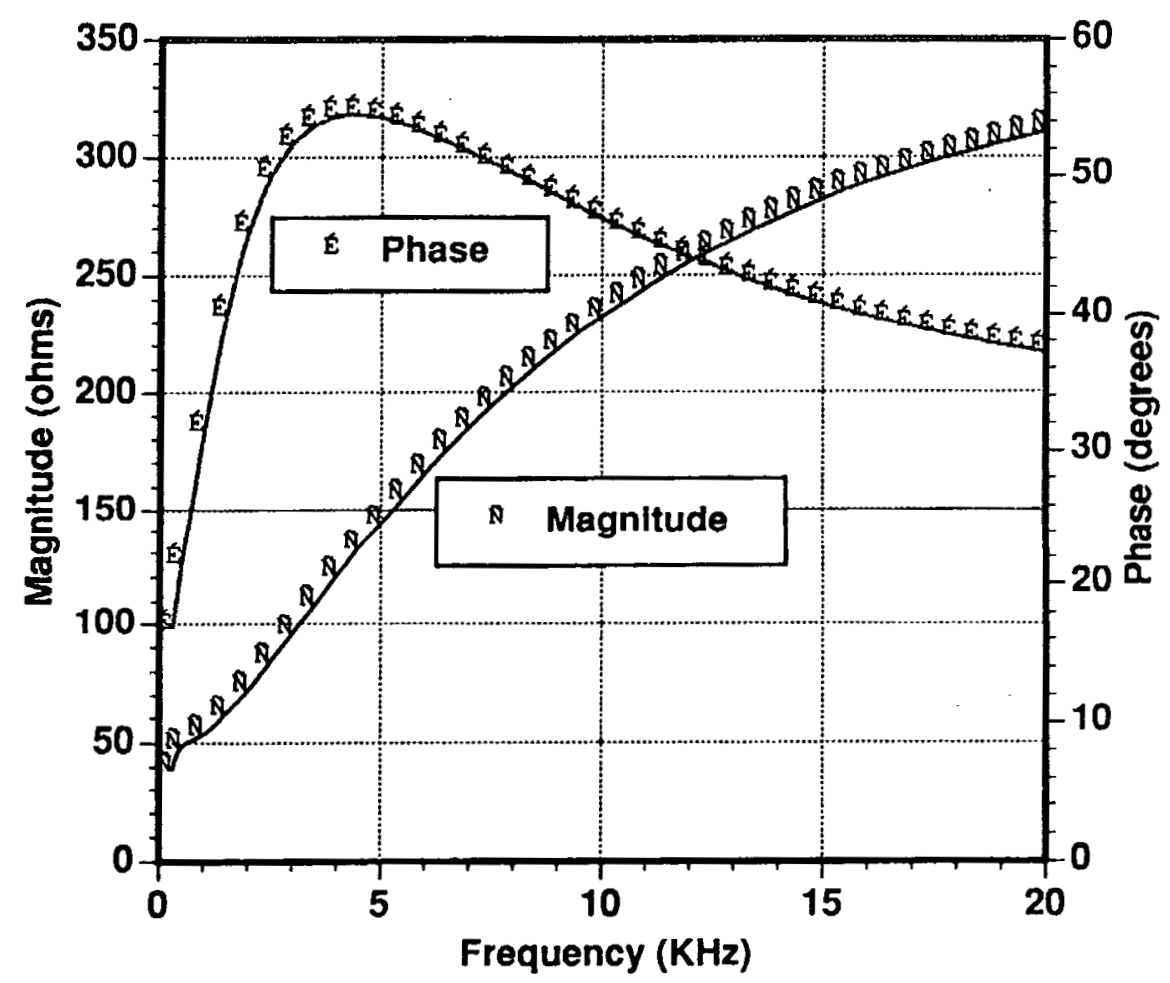

Figure 4.17. Magnitude and Phase of the Coil Electrical Impedance Versus Frequency 


\subsubsection{Future Work}

Equipment necessary to complete this task has been thoroughly tested and is ready for moisture and temperature calibration studies. A particular simulant can now be calibrated for moisture content in a 4-week time frame using the existing measurement system. Each additional simulant will require 2 weeks for calibration.

Moisture measurement studies will proceed with calibration tests on appropriate simulants. The moisture measurement system will be calibrated first by measuring a simulant's electrical resistance and temperature, and then correlating the results with an accurate chemical analysis to determine the free water content. Performing this procedure on a wide variety of simulants will provide information on how sensitive the calibration parameters are for different types of waste materials known to exist in SSTs.

Continued funding for FY 1991 has not yet become available. This work can resume as soon as mid-year funding is identified.

\subsection{Tank Waste Science Panel}

The Tank Waste Science Panel met February 7-8, 1991, and was briefed on the ferrocyanide issues to be addressed (Strachan 1991). Specifically, the panel is examining the chemistry and physics of waste in tanks containing ferrocyanide. During the February meeting members were briefed on the ferrocyanide process used in the 1950 s to remove the ${ }^{137} \mathrm{Cs}$ from the Bismuth Phosphate wastes at Hanford and what is known about the chemistry of the process. Subsequent work in FY 1991 for Task 4.6 of the Ferrocyanide Safety Project included a summary document to the panel describing the existing cell current data on the ferrocyanide tanks (Burger et al. 1991). 


\subsection{References}

Borsheim, G. L., and B. C. Simpson. 1991. An Assessment of the Inventories of the Ferrocyanide Watchlist Tanks.. WHC-SD-WM-ER-133 Rev. 0, Westinghouse Hanford Co., Richland, Washington.

Burger, L. L. 1984. Complexant Stability Investigation, Task 1 - Ferrocyanide Solids. PNL-5441, Pacific Northwest Laboratory, Richland, Washington.

Burger, L. L., and R. D. Scheele. 1988. Interim Report - Cyanide Safety Studies. PNL-7175, Pacific Northwest Laboratory, Richland, Washington.

Burger, L. L., and R. D. Scheele. 1991. The Reactivity of Cesium Nickel Ferrocyanide Towards Nitrate and Nitrite Salts - A Status Report. PNL-7550, prepared for the Tank Waste Science Panel by Pacific Northwest Laboratory, Richland, Washington.

Burger, L. L., D. A. Reynolds, W. W. Schultz, and D. M. Strachan. 1991. A Summary of Available Information on Ferrocyanide Tank Wastes. PNL-7822, Pacific Northwest Laboratory, Richland, Washington.

Defense Nuclear Facilities Safety Board (DNFSB). 1990. "Implementation Plan for Recommendation 90-3 at the Department of Energy's Hanford Site, Washington." DNFSB Recommendation No. 90-7. Federal Register, Vol. 55, No. 202, pp. 42243-42244.

Peach, J. D. 1990. "Consequences of Explosion of Hanford's Single-Shell Tanks are Underestimated." Letter B-241479 dated October 1990 to M. Synar, GAO/RCED-91-34, General Accounting Office, Washington, D.C.

Scheele, R. D., and H. H. Cady. 1992. Preliminary Safe-Handling Experiments on a Mixture of Cesium Nickel Ferrocyanides and Equimolar Sodium Nitrate/Nitrite. PNL-7928, Pacific Northwest Laboratory, Richland, Washington.

Shamaev, V. I., T. V. Chudnovskikh, and I. M. Pavlidi. 1982. "Coprecipitation of Cesium with Copper, Cobalt, Nickel, and Mercury Ferrocyanides as a Method for Their Separation From Other Alkali Elements." Radiokhimiya 24(2):198-203, March-April. Plenum Publishing Corporation.

Strachan, D. M. 1991. Minutes of the Tank Waste Science Meeting, February 7-8, 1991. PNL-7709, prepared for the Tank Waste Science Panel by Pacific Northwest Laboratory, Richland, Washington.

Tananaev, I. V., M. A. Glushkova, and G. B. Seifer. 1956. "The Solubility Series of Ferrocyanides." Journal of Inorganic Chemistry (USSR) I(1):66-68.

U.S. Department of Energy (DOE). 1987. Final Environmental Impact Statement, Disposal of Hanford Defense High-Level, Transuranic, and Tank Wastes. DOE-EIS-0113, Washington, D.C.

U.S. Department of Energy (DOE). 1990. "DOE to Develop Supplemental Environmental Impact Statement for Hanford." Press Release, October 9, 1990, Washington, D.C.

Wagman, D. D., et al. 1982. "The NBS Tables of Chemical Thermodynamic Properties - Selected Values for Inorganic and $C_{1}$ and $C_{2}$ Organic Substances in SI Units." J. Phys. Chem. Ref. Data 11. Suppl. No. 2. 


\section{Distribution}

No. of

Copies

OFFSITE

12 DOE/Office of Scientific and Technical Information

25 U.S. Department of Energy EM-35, Trevion II Washington, DC 20585

J. C. Tseng

U.S. Department of Energy Idaho Operations Office 785 DOE Place Idaho Falls, ID 83402

P. G. Woodall

U.S. Department of Energy Savannah River Operations Office P.O. Box A

Aiken, SC 29808

C. Terrell

5

C. S. Abrams 1987 Virginia

Idaho Falls, ID 83404

D. O. Campbell

102 Windham Road

Oak Ridge, TN 37830

F. N. Carlson

6965 North 5th West

Idaho Falls, ID 83401

D. T. Oakley

409 12th Street SW, Suite 310

Washington, DC 20024-2188

A. K. Postma 3640 Ballard Road

Dallis, OR 97338
No. of

Copies

Air Products \& Chemicals

7201 Hamilton Blvd.

Allentown, PA 18195-1501

G. E. Schmauch

2 Brookhaven National Laboratory Upton, NY 11973

K. K. Bandyopadhyay

M. Reich

EG\&G Idaho, Inc.

P.O. Box 1625

Idaho Falls, ID 83415

W. C. Schutte

Fauske and Associates, Inc.

16 W070 W. 83rd St.

Burr Ridge, IL 60521

H. K. Fauske

Harvard University

295 Upland Avenue

Newton Highlands, MA 02161

M. W. First

Lawrence Livermore National

Laboratory

P.O. Box 808, L-221

Livermore, CA 94550

B. C. Hudson

4 Los Alamos National Laboratory

Los Alamos, NM 87545

S. Eisenhawer

T. E. Larson

J. W. Spore

H. Sullivan

MIT/Dept of Nuclear Eng.

77 Massachusetts Ave.

Room 24-102

Cambridge, MA 02193

M. S. Kazimi

Distr. 1 
No. of

Copies

3

Oak Ridge National Laboratory

Charles W. Forsberg

105 Mitchell Road

MS-6495

Oak Ridge, TN 37831

T. S. Kress

P.O. Box 2009, MS-8088

Oak Ridge, TN 37831-2009

D. J. Pruett

P.O. Box 2008

Building 4501, MS-6223

Oak Ridge, TN 37831

Rice University

5211 Paisley

Houston, TX 77069

A. S. Velentsos

Sandia National Laboratory

P.O. Box 5800

Albuquerque, NM 87185

S. E. Slezak

4

Science Applications International

Corporation

12850 Middlebrook Road

Trevion I, Suite 300

Germantown, MD 20874

R. S. Daniels (3)

J. M. Saveland

West Valley Nuclear Services Co., Inc. Rock Springs Road (Box 191)

West Valley, NY 14171

D. K. Ploetz

Westinghouse Idaho Nuclear Co., Inc. 1955 Freemont Ave.

P.O. Box 4000

Idaho Falls, ID 83403-4000

A. P. Hoskins
No. of

Copies

Westinghouse Savannah River

Company

P.O. Box 616, 703-H

Aiken, SC 29802

P. d'Entremont

\section{ONSITE}

5 U.S. Department of Energy, Richland Field Office

R. F. Christensen, A4-02

R. E. Gerton, A4-02

W. F. Hendrickson, N2-56

G. Rosenwald, A5-21

Public Reading Room, A1-65

51 Westinghouse Hanford Company

H. K. Ananda, S1-57

J. M. Atwood, SO-61

H. Babad, R2-31

D. B. Bechtold, T6-50

M. L. Bell, T6-16

R. M. Black, R1-19

R. J. Blanchard, R1-17

K. D. Bonser, R1-67

G. L. Borsheim, R2-11

R. J. Cash (5), R2-31

R. D. Crowe, H5-32

C. DeFigh-Price, B4-55

D. R. Dickinson, L5-31

G. T. Dukelow (2), R2-32

C. J. Forbes, R1-08

J. C. Fulton, R2-31

K. A. Gasper, R2-08

J. M. Grisby, H5-32

C. S. Haller, R2-18

T. W. Halverson, T5-49

D. G. Hamrick, R1-51

H. D. Harmon, R2-52

D. L. Heer, H0-38

R. D. House, R2-83

M. N. Islam, R3-08

Distr. 2 
No. of Copies

Westinghouse Hanford Company (contd)

D. W. Jeppson, L5-31

J. R. Jewett, T6-50

N. W. Kirch, R2-11

W. L. Knecht, H0-34

M. Kummerer, H5-32

D. L. Lenseigne, R2-75

J. M. McLaren, H0-34

J. D. McCormack, L5-31

C. R. Miska, R2-08

A. F. Noonan, R2-12

R. S. Popielarczyk, R1-30

J. G. Propson, R2-18

R. E. Raymond, R1-80

I. E. Reep, R2-08

D. A. Reynolds, R2-11

D. C. Richardson, R2-31

C. P. Schroeder, L7-06

M. H. Shannon, H5-30

H. Toffer, H0-38

R. K. Welty, R1-80

W. F. Zuroff, R2-14
No. of

Copies

29 Pacific Northwest Laboratory

S. A. Bryan, P7-25

L. L. Burger, P7-25

M. S. Hanson, K1-51

R. T. Hallen (10), P8-38

B. M. Johnson (3), K1-78

M. A. Lilga, P8-38

J.T.A. Roberts, K1-73

R. A. Romine, P8-38

R. D. Scheele, P7-25

G. F. Schiefelbein, P8-38

D. M. Strachan, K2-38

J. M. Tingey, P7-25

Publishing Coordination

Technical Report Files (5)

Distr. 3 